\title{
Señderes
}

\section{La escuela rural latinoamericana en PISA: el olvido reciente ${ }^{1}$}

\author{
The Latin American rural school in PISA: \\ the recent forgetfulness
}

\section{Autores \\ Rogeli Santamaría Luna ${ }^{2}$}

Recibido: 16 de agosto de 2017 .

Aprobado: 10 de noviembre de 2017.

1 Reflexión académica del autor sustentada a partir de sus distintas actividades en la Red Iberoamericana de Educación en Territorios Rurales y otros foros sobre educación rural y evaluaciones externas.

2 Diplomado en Escuela Universitaria de Formación del Profesorado de EGB, Castellón. Licenciado en Filosofía y Ciencias de la Educación de la Universidad de Valencia. Doctor en Educación. Universitat Jaume I. Castellón. Master calidad Sistema Educativo de la Universitat Politécnica, Valencia. Inspector de educación. Inspección Territorial de Educación. Dirección Territorial de Educación, Investigación, Cultura y Deporte. Castellón de la Plana, España. roges162@gmail.com

\section{Resumen}

El Programa para la Evaluación Internacional de Alumnos de la Organización para la Cooperación y el Desarrollo Económico (Programme for International Student Assessment) puede mejorar el conocimiento sobre la educación rural, mostrar sus debilidades y fortalezas, dar una imagen estereotipada y errónea de la escuela rural o invisibilizar sus realidades. En este artículo se evidencia la ruralidad en PISA en las distintas rondas, más visible siempre en América Latina que en España y Portugal. En la ronda 2012 la brecha urbano-rural oscila entre 28 y 89 puntos y apenas se atiende el tema rural, que casi es obviado en los cuatro volúmenes de resultados que se publicaron de la ronda 2015. Analizar los resultados en América Latina permite aprender de países próximos, animar a las instituciones a atender este factor y a los investigadores a profundizar en su conocimiento para argumentar en favor de la educación rural y la equidad.

Palabras clave: América Latina, evaluación de la educación rural 


\section{Abstract}

The Program for the International Student Assessment of the Organization for Economic Cooperation and Development (Program for the International Evaluation of Students in English) can improve knowledge about rural education, show its weaknesses and strengths, give a stereotyped and of the rural school or to make their realities invisible. This article shows the rural condition in PISA in the different rounds, more visible in Latin America than in Spain and Portugal. In the 2012 round, the urban-rural gap is between 28 and 89 points, and penalties are in the rural area, which is almost obviated in the four volumes of results of the 2015 round published. Analyzing the results in Latin America allows to learn from the next countries, encourage institutions to address this factor and researchers to deepen their knowledge for the argument in favor of rural education and equity.

Key words: Latin America, rural education evaluation

\section{Introducción}

Este artículo deriva del material bibliográfico y analítico recopilado por el autor a lo largo de su trayectoria docente e investigadora sobre el rendimiento escolar diferencial urbano-rural, porque algunas publicaciones han mantenido ocultos factores explicativos de los resultados rurales o han obviado los buenos resultados educativos en aspectos sociales (integración, convivencia, participación, compañerismo, autonomía, etc.) que los docentes rurales sí aprecian (Santamaría, 1996; Weinstein, 2016).

Las evaluaciones estandarizadas suelen considerar el factor ubicación (ruralurbana) y otros que pueden mostrar diferencias de partida (niveles de estudios de progenitores, nivel socioeconómico, asistencia a preescolar, idioma de la prueba diferente del que utilizan en casa). Especialmente las pruebas internacionales, no vinculadas a gobiernos, ofrecen datos para comparar resultados, tendencias, evoluciones y realidades diversas así como políticas variadas, y presentan fortaleza en sus argumentos y mesura en sus propuestas, desvinculadas de gobiernos que usan los "malos resultados de la escuela rural" para justificar el cierre de las escuelas rurales, como viene ocurriendo de forma reiterada en muchas partes del mundo. Así se manifiesta en estudios como "Contra el mito de la mala calidad de la escuela rural" o "Evaluaciones externas y la educación rural”.

Con este trabajo se pretende animar a los investigadores a enfocar sus estudios hacia la educación rural, aprovechando la publicación de informes y bases de datos del Programa para la Evaluación Internacional de Alumnos (Programme for International Student Assessment -PISA-) que la Organización para la Cooperación y el Desarrollo Económico — OCDE - pone a disposición del público. El estudio de estas fuentes permitirá mejorar el conocimiento sobre la educación rural y mostrar sus debilidades y fortalezas, porque las bases de datos PISA incluyen la ubicación del centro escolar al que asiste el alumnado, considerando que el factor rural puede influir en los resultados, pero la realidad de los informes oficiales de resultados PISA 
parece ocultarlo o minimizar su importancia, pese a ser uno de los factores que más influyen en los resultados en Latinoamérica, como demostraremos.

El medio rural puede analizarse en contraposición al medio urbano como entes dicotómicos donde predomina más factor (tradicional-moderno, oprimido-opresor, conservador-liberal), pero la realidad es un continuo rural-urbano y a veces resulta difícil definir lo rural o lo urbano. Además de los criterios dicotómicos, se deberían combinar otros criterios (demográfico, ecológico, ocupacional, funcional, cultural, etc.) que varían de un lugar a otro. La Unesco en su web define los asentamientos con menos de 10.000 habitantes como rurales:

Los pobladores rurales representan el 70 por ciento de la población mundial y el 72 por ciento de los habitantes de los países menos desarrollados. Las desigualdades entre el campo y la ciudad constituyen un obstáculo importante al desarrollo sostenible. Las zonas rurales comprenden asentamientos humanos de menos de 10.000 habitantes y en el espacio rural predominan las granjas, los bosques, los ríos y lagos, las montañas o el desierto. (Unesco, 2017)

De ahí la importancia que concede la Unesco a la población rural y la ruralidad aparece frecuentemente en sus publicaciones. Así, en el informe La Educación para Todos, 2000-2015: logros y desafíos encontramos 167 referencias directas al medio rural (Unesco, 2015).

El Banco Mundial ofrece datos mucho más bajos. En 1960, el porcentaje de población rural mundial era de $66 \%$, cifra que se reduce a $46 \%$ en 2016. En la OCDE varía de 38 a $20 \%$, en América Latina y El Caribe baja de 51 a $20 \%$ y en la Unión Europea disminuye el porcentaje de población rural de 38 a 25 (Banco Mundial, 2017a). La disminución del peso de la población rural en el mundo y en estas economías o regiones puede suponer la invisibilización de la educación rural, fenómeno que constataremos en PISA. Pero la realidad es que la población rural sigue aumentando en todo la Tierra: en 1960 había unos 2.000 millones y son 3.390 en 2016; América Latina y El Caribe han aumentado levemente la población rural de 112 millones a 127; la OCDE la reduce de 296 a 252 millones en ese período y la Unión Europea también, de 159 a 128 millones. Se observa una dinámica de crecimiento fuerte en el mundo, muy fuerte en África, en el sureste asiático o en los países árabes; en los países de América Latina y El Caribe, con excepción de Argentina, Brasil, Chile y Uruguay, ha aumentado su población rural, lo que ha contribuido a un leve aumento; en cambio la pérdida de población rural en economías como la OCDE y la Unión Europea es patente (Banco Mundial, 2017b). Por este motivo, atender exclusivamente al porcentaje de población puede confundir y orientar políticas erróneas sobre la población rural.

En América Latina se utilizan diferentes tipos de criterios para la definición censal de lo rural: algunos países consideran número de personas por localidad, en otros casos se agrega a este criterio el empleo en actividades primarias, otros consideran el número de casas contiguas; también, a veces, la presencia o no de servicios públicos 
o la capitalidad de distrito (Itzcovich, 2012, pp. 30-31). Esta diversidad de criterios dificulta las comparaciones de lo rural. Incluso puede haber una subestimación del porcentaje de población rural latinoamericana, que varía del 22 al $42 \%$, según las fuentes empleadas (Itzcovich, 2010, p. 29), por lo que también en América Latina se podría producir la reducción de la representación rural en las investigaciones citadas en Europa, con escasa producción en español en comparación con la producción científica en inglés sobre educación rural (Bustos, 2011).

En esta región hay gran diversidad ecológica por diferencias de altitud y latitud (llanuras litorales y cadenas montañosas, zonas australes, tropicales y ecuatoriales), parajes en distintas fases de transformación del medio natural con la pugna entre la sostenibilidad tradicional y la explotación poco racional. Además, se estima que en la región existen más de 520 pueblos indígenas que hablan más de 400 lenguas y representan unos 50 millones de personas distribuidas de manera muy desigual en las distintas zonas y países, lo que genera una complejidad mayor en esta región (Kit, Scasso, España y Morduchowicz, 2012, p. 22). Ahí se evidencia una de las principales marginaciones en la educación desruralizadora, pensada desde la capital por las mentes urbanas para "salvar a los rurales de su incultura” y garantizar la "equidad e igualdad de oportunidades”, porque consideran que sólo hay un modelo de desarrollo socioeconómico y cultural válido, el suyo, al que todos deben aspirar (Contreras, 2010, p. 5; Santamaría, 2015a, pp. 82-83).

La falta de argumentos sólidos para la defensa de la escuela rural es un error que las comunidades rurales no pueden permitirse, puesto que como el imaginario rural mantiene que cerrar la escuela es matar el pueblo, expresión que conviene actualizar porque la mejora de la educación facilita el establecimiento de jóvenes, la mejora del capital humano y del desarrollo socioeconómico, lo que posibilita la sostenibilidad demográfica y potencia un círculo virtuoso para el medio rural a partir de las ventajas que tienen las pequeñas escuelas como ratios más reducidas (Fuster, 2017). La reiterada mala calidad de la escuela rural es un argumento fácil de esgrimir, basado en el desconocimiento educativo de los que lo utilizan con una base metodológica empírica de grandes números descontextualizados, inadecuada para valorar muestras reducidas para las que se requiere una metodología empírica mixta cuantitativacualitativa, casi sustentada en el estudio de casos.

No obstante, los datos sobre rendimientos escolares diferenciales rural/urbano son variados y diversos y no siempre apuntan a la inferioridad rural (Quílez y Vázquez, 2012; Santamaría, 2012), y por eso ahora es pertinente recordarlo e, incluso, difundir informes que discuten la hipótesis de calidad inferior de la escuela rural, como PISA 2003, que muestra descontando el efecto socioeconómico del alumnado y de la escuela, los resultados de la escuela rural no son peores que los de zonas urbanas (OECD, 2004, p. 260), aunque en las rondas posteriores generalmente los rurales puntúan debajo en muchos países, con excepciones (OECD, 2008a, p. 217; 2010, p. 14; 2013, pp. 69-71) y con los matices necesarios respecto de los contextos. Todo ello conduce a considerar que si los resultados son peores hay que actuar para mejorarlos 
y no escudarse en defectos de muestreo o en las condiciones de las comunidades rurales, del alumnado y de las escuelas para justificar los resultados, opción que dificulta la mejora.

De no reconocer las diferencias y las posibilidades de mejora se corre el riesgo de que la mentira, de tanto repetirla, se convierta en verdad y la población rural crea que la educación que disfrutan sus hijos es mucho peor que la ofrecida en otras zonas y que por ello sus hijos tendrán resultados peores y menos expectativas y, en definitiva, si quieren que sus hijos mejoren su formación los enviarán a centros urbanos, lo que favorecería el cierre de escuelas y el éxodo rural. Es un ejemplo claro de la dualidad rural/urbano como oprimido/opresor, en la que se pretende que el oprimido asuma como propios los principios del opresor (Freire, 1982, pp.52-53; Santamaría, 1996, p. 113-115).

Para conocer la realidad educativa rural latinoamericana podemos encontrar muchas referencias, pero las resumimos en la siguiente cita:

La zona rural también se encuentra en una situación de desigualdad, mostrando mayores tasas de repetición y deserción que la zona urbana. El promedio regional de personas entre 15 y 24 años que tiene por lo menos 10 años de educación es del $50 \%$ en las zonas urbanas mientras que en las zonas rurales el promedio llega aproximadamente al $20 \%$. En el medio rural muchas escuelas no imparten la enseñanza obligatoria completa, son de difícil acceso y en muchos casos cuentan con docentes menos calificados.

Los niños y jóvenes provenientes de pueblos originarios o afro-descendientes también se encuentran en situación de desigualdad educativa y social. Estos colectivos suelen vivir en la zona rural o zonas aisladas, donde como ya se ha visto también hay mayores índices de pobreza, por lo que son objeto de diferentes tipos de discriminación. En los países que cuentan con datos desagregados, los índices de repetición, abandono y analfabetismo son mayores en el caso de los pueblos originarios. En los últimos años ha habido un mayor avance en la educación intercultural y bilingüe, pero este es aún muy insuficiente. (Blanco, 2006, p. 3).

Las brechas en España y Portugal no son tan acusadas, pero existen, y las de América Latina van reduciéndose, pero muy lentamente. Estas brechas socioeducativas afectan los resultados escolares.

La OCDE con PISA intenta evaluar las competencias en comprensión lectora, matemáticas y ciencias naturales del alumnado de quince años escolarizado para comparar datos entre los países y su evolución temporal, así como efectos de algunos factores y sugerir directrices al respecto. Cada tres años se realiza una nueva ronda para evaluar estas competencias, aunque cada ronda propicia investigaciones focales, más exhaustivas y centradas en una de las competencias. En 2012 la competencia focal fue matemáticas y en 2015, ciencias. En las dos últimas rondas hay competencias opcionales para evaluar por 
los países participantes, como la resolución de problemas y las competencias financieras. Para aplicar la prueba se elaboran cuadernillos con unidades de evaluación compuestos de preguntas de respuesta múltiple y otras en las que los examinados formulan sus propias respuestas. Las unidades están organizadas en grupos basados en escenarios que exponen una situación de la vida real. Los alumnos deben cumplimentar sus cuadernillos en presencia de un evaluador externo, que traslada las pruebas para su corrección fuera del centro. Los datos obtenidos se refieren exclusivamente a las competencias evaluadas y al nivel de logro alcanzado, aunque se ponderan con informaciones del entorno obtenidas mediante cuestionarios (de alumnado, de directores de centros y del profesorado) que permiten definir factores contextuales como el nivel socioeconómico del alumno y del centro y estudiar el impacto de factores asociados al rendimiento en las distintas pruebas.

Las dos últimas rondas se han aplicado por ordenador para facilitar su difusión y uso. PISA intenta superar las críticas que surgen en cada ronda para fortalecer su metodología. En 2015 se ofrecieron cuestionarios de ampliación sobre actitudes del alumno, historial, hábitos de estudio, expectativas, clima escolar, acoso, relaciones con el profesorado y valoraciones personales sobre algunos temas; al profesorado se le ha preguntado sobre su experiencia y práctica docente, metodología y formación en relación con las ciencias (OCDE, 2016c, p. 3); a las familias, sobre sus relaciones con sus hijos, con el centro o con el profesorado. Pero el uso opcional de estos cuestionarios en los distintos países no confiere la fiabilidad deseada para cada uno de ellos.

En estos quince años PISA ha evolucionado. Inicialmente realizaban las pruebas e informes de comparación, pero recientemente ha ampliado sus líneas de actuación con PISA para el desarrollo, orientada a proporcionar instrumentos que favorezcan el desarrollo de los países a partir de la educación y PISA para centros, que enfoca el estudio de todo el centro escolar (no sólo grupos de muestra) para ofrecerle orientaciones de mejora.

La evolución de PISA para el desarrollo puede ser un instrumento muy útil para mejorar la educación latinoamericana, especialmente si se relaciona con estudios compa-rativos procedentes de otras fuentes. En el informe Making Education Count for Development: Data Collection and Availability in Six PISA for Development Countries (UIS, 2016) se presentan datos de seis países entre los que se encuentran Ecuador, Guatemala y Paraguay, pero no hay referencias a ruralidad, en contra de las veinte referencias del informe anterior The Experience of Middle-Income Countries Participating in PISA 2000-2015 (Lockheed, Prokic-Bruer y Shadrova, 2015). Parece como si lo rural importara menos en PISA para el desarrollo.

Las primeras pruebas PISA se aplicaron el año 2000 en veintiocho países de la OCDE y cuatro de otras economías. Iberoamericanos son Brasil, España, México y Portugal. Sólo dos años después se amplió la aplicación hasta lograr 43 países participantes de los cuales había tres latinoamericanos más: Argentina, Chile y Perú (OECD, 2001, p. 14). 
Desde la ronda 2000 hasta 2006 ha habido mucha variación en la participación de países iberoamericanos. En 2003 no participaron Argentina, Chile y Perú, pero se incorporó Uruguay. En 2006 se sumó Colombia con la reincorporación de Argentina y Chile.

En ese momento los ocho países citados compartían parte de su herencia cultural y lenguas, y algunos países tenían poca experiencia en evaluación de aprendizajes mediante instrumentos estandarizados de aplicación a gran escala (preparación de estudios, diseño, muestreo, pilotaje, cuestionarios de contexto y pruebas de logros, análisis de datos y comparaciones, etc.) que permitieran ofrecer elementos útiles para sustentar políticas dirigidas a mejorar la calidad educativa. La colaboración de los grupos PISA de estos países generó el Grupo Iberoamericano de PISA (GIP) que elaboró el informe Iberoamérica en PISA 2006. Informe regional, con la implementación y los aprendizajes de los ocho informes nacionales. Además, el GIP formuló propuestas a la OCDE que permitieran una mejor adaptación de las pruebas a los contextos iberoamericanos (GIP, 2009, pp. 7-8).

En 2009 se incorporó Costa Rica y volvió a participar Perú. En 2012 no varió la participación de países del GIP y República Dominicana ingresó en PISA 2015, ronda en la que participaron 72 países. La participación de países iberoamericanos ha aumentado más que la media, se multiplicó en 15 años por 2,75 frente a 2,25 del total, debido a la fuerte presión que sienten al respecto desde dentro (uso de resultados PISA como arma política) y desde fuera (uso de datos PISA en valoraciones de cada país, vinculados a proyectos con la OCDE, el Banco Interamericano de Desarrollo — BIDo de otros organismos internacionales), sin olvidar que realmente su participación les permite "compararse" con otros y analizar también su propia evolución, para mejorar sus procesos de evaluación del sistema educativo.

Con este trabajo se pretende poner en evidencia la utilidad de PISA como fuente de datos y la necesidad de contextualizarlos para evitar generalizaciones incorrectas e injustas. La imagen de una escuela rural de la mala calidad que se desprende de los informes PISA puede provocar políticas educativas nefastas para la población rural y para el desarrollo de América Latina. De ahí la importancia de involucrar a los investigadores, en las universidades y en las escuelas, para que profundicen en los datos y las propuestas derivadas, los valoren y critiquen, se apropien de la información y la hagan suya, en sus lenguas y para sus comunidades. Sólo así podrá aprovecharse el esfuerzo común de PISA para que los actores educativos mejoren la escuela rural y ésta influya en el desarrollo comunitario, sobre todo si son capaces de difundir sus estudios, observaciones y buenas prácticas en español, portugués u otras lenguas de la región, poniendo el foco en la educación rural que se hará más visible en la bibliografía pedagógica. A su vez, debe servir para llamar la atención de los organismos internacionales que en sus informes sobre educación y desarrollo parecen olvidar la educación en zonas rurales. 
A continuación se explica la metodología empleada en el estudio y se aportan resultados a partir de los informes y tablas de datos, que se deberían contrastar con otras fuentes e investigaciones. Finalmente se presentan conclusiones, propuestas y unas sesenta referencias bibliográficas.

\section{Metodología}

El autor parte de una recopilación bibliográfica sobre rendimiento escolar diferencial rural/urbano iniciada en 1991, actualizada en 2012 y centrada en la evolución de PISA 2012-2015 para los países iberoamericanos que participaron, a partir de las publicaciones digitales de la OCDE. En estas publicaciones se ha computado la frecuencia de la palabra "rural" para entender a qué se refiere y su presencia en los distintos informes, así como las relaciones de ruralidad con otros factores.

En PISA 2000 se revisaron ocho informes, entre los que se destacan Measuring Student Knowledge and Skills: The PISA 2000 Assessment of Reading, Mathematical and Scientific Literacy (OECD, 2000), y Knowledge and Skills for Life: First Results from PISA 2000 (OECD, 2001), que debieron aportar información sobre la ruralidad, pero apenas hubo referencias. En el primer informe de resultados de PISA 2000 no hay datos sobre rendimiento rural (OECD, 2002b), pese a considerar el grado de urbanización/ruralidad y el tratamiento diferencial de las escuelas pequeñas en la estratificación de las muestras (OECD, 2002a, pp. 45-47) y en la determinación de ubicaciones: 1. Pueblo (menos de 3.000 habitantes); 2. Pequeña ciudad (3.000 a 15.000); 3. Ciudad (15.000 a 100.000); 4. Ciudad (100.000 a 1.000.000); 5. Gran ciudad-centro (más de 1.000.000), y 6. Gran ciudad-otras (más de 1.000.000) (OECD, 2002c, p. 111). No obstante, se aprecia ya una subestimación rural, puesto que algún país excluye las escuelas muy pequeñas, alejadas geográficamente o en gran desventaja (OECD/UIS, 2003, p. 253).

Sorprendidos por la escasez de referencias al medio rural en los primeros informes PISA, pese a constatar la ruralidad como uno de los factores de contexto, en otros informes de las distintas rondas, especialmente en los volúmenes referidos a equidad e igualdad en educación, rastreamos datos que presentamos en el apartado de resultados, donde el lector podrá encontrar referencias a páginas o tablas para consultar directamente los países de su interés. Merece destacarse la ronda 2003, porque supuso un cambio en la asignación de localizaciones, uniendo las anteriores 5 y 6 (ciudades de más de un millón de habitantes) en una única: 5. Ciudad de más de un millón de habitantes (OECD, 2005b, p. 127), que constan en las trece referencias a rural del Manual de análisis de datos y que PISA mantiene desde entonces en todas las rondas. Sin embargo, en el informe Learning for Tomorrow's World: First Results from PISA 2003 (OECD, 2004) encontramos sólo trece referencias a rural las cuales se reducen a dos que se refieren a la brecha de resultados urbano-rural.

En la ronda 2006, enfocada a la enseñanza de las ciencias, en el volumen I (OECD, 2007) hay siete referencias a rural que no explican suficientemente las diferencias que podemos encontrar en el volumen II (OECD, 2008a). Sin embargo, los datos 
de PISA para países iberoamericanos fueron estudiados de forma específica en el informe regional Iberoamérica en PISA 2006 (GIP, 2009), que contiene 80 referencias a rural y propone metodología de análisis y medidas para mejorar PISA en los países estudiados, aunque el grupo no las aplica en su propio informe y algunas han sido consideradas con posterioridad. Pese a las referencias a rural, no se analiza con profundidad el impacto de este factor en los resultados de PISA o en las condiciones del alumnado y las escuelas, ni con la amplitud suficiente que permita proponer pautas específicas para posteriores rondas PISA o en las evaluaciones nacionales respecto de la educación rural.

Posteriormente, las rondas 2009 y 2012 siguen el esquema de estudio del factor rural definido en 2003 y analizan el diferencial urbano-rural en sendos informes: PISA 2009 Results: Overcoming Social Background: Equity in Learning Opportunities and Outcomes (Volume II) y PISA 2012 Results: Excellence Through Equity: Giving Every Student the Chance to Succeed (Volume II); hay aproximadamente una página dedicada a la influencia del factor rural en los resultados de PISA, con conclusiones parecidas a las indicadas en rondas anteriores.

Cabe mencionar la publicación en 2015 de dos estudios sobre PISA en países iberoamericanos o de ingresos medios, en los que podemos encontrar frecuentes referencias a rural: América Latina después de PISA: Lecciones aprendidas de la educación en siete países 2000-2015 (Rivas, 2015) con 36 referencias a rural, y The Experience of Middle-Income Countries Participating in PISA 2000-2015 (Lockheed, Prokic-Bruer y Shadrova, 2015) con 20 referencias a rural y análisis de 18 países de ingresos medios.

Después de estas publicaciones, y con la vista puesta en PISA para el desarrollo y la ruralidad, no hemos encontrado ninguna referencia a resultados rurales diferenciales en el informe PISA 2015 Results (Volume I): Excellence and Equity in Education (OECD, 2016a). Sin embargo, el informe PISA 2015 Results (Volume II): Policies and Practices for Successful Schools (OECD, 2016b), contiene múltiples referencias sobre opiniones obtenidas de los cuestionarios aplicados a alumnado, profesorado, directivos o familias y en algunas se considera el factor rural, lo cual permite orientar buenas prácticas que, en algunos casos, son mejores en zonas rurales. Lo mismo ocurre en PISA 2015 Results (Volume III): Students' Well-Being (OECD, 2017a), que aborda temas como índice de acoso escolar, la frecuencia de acoso o las expectativas de continuar en la universidad en relación con las características de las escuelas, y evidencia diferencias entre urbano y rural. Finalmente, PISA 2015 Results (Volume IV): Students' Financial Literacy (OECD, 2017b) analiza los logros en competencias financieras del alumnado de 15 países de los 72 que participaron en esta ronda. Entre ellos se encuentran Brasil, Chile, España y Perú, y se evidencia el peso del factor rural en esta competencia. Como conclusión de los informes PISA 2015 podemos decir que no aportan datos sobre el diferencial urbano-rural en las competencias medidas, excepto la competencia financiera, en la que generalmente los rurales rinden menos. Sin embargo, sí aportan datos sobre tendencias, opiniones y maneras de trabajar 
supuestamente diferentes que podrían influir en los resultados educativos, y pueden ser una fuente importante de datos sobre la educación rural que muestran que, en algunos casos, puede ser mejor que la urbana, dato que sugiere un cambio de paradigma sobre la educación rural, que ya no es siempre sinónimo de calidad inferior sino que es diferente y de ella se puede aprender.

En el apartado "Resultados" hay varias partes totalmente diferenciadas, la referida a ruralidad y evaluaciones externas en Latinoamérica, España y Portugal, PISA y la educación rural, los informes textuales anteriores a 2012 y los recientes, como cronología bibliográfica comentada, para cerrar con el apartado de datos actualizados.

Los informes de PISA 2015 no presentan datos sobre competencias vinculados a la ubicación geográfica, por lo que hemos recurrido al explorador de datos de PISA 2015 mediante el enlace http://pisadataexplorer.oecd.org/ide/idepisa/. Este instrumento permite obtener la media de cada una de las competencias evaluadas en PISA desde 2000 hasta 2015, con indicación del error estándar en las tablas iniciales (pestaña TABLE) y puede realizar gráficas automáticamente (pestaña CHART). A su vez permite comparar medias por jurisdicciones territoriales, variables personales (género, edad, repetición de curso, preescolarización, nivel de estudios y laboral de los padres, posesiones, NSEC), variables del centro (ubicación, titularidad, etc.), así como opiniones con base en cuestionarios. En las comparaciones estima si la diferencia entre medias es significativa (pestaña SING), y genera tablas independientes con un nivel Alfa de ०,०5, con algunas limitaciones.

En este estudio se ha trabajado con medias y cómo influye en cada jurisdicción la ubicación de la escuela para definir si realmente este factor influye o no, si hay diferencias entre jurisdicciones y entre años. Se completa la información con algunas tablas y gráficas obtenidas de distintos informes PISA, del explorador o de otras fuentes, y se intenta relacionar los resultados ofrecidos con los de otras investigaciones.

\section{Resultados: Las evaluaciones estandarizadas y la escuela rural en Latinoamérica, España y Portugal}

En el contexto actual de América Latina, buscar el éxito en los sistemas educativos se vincula a que las escuelas hagan públicos sus resultados, puesto que la transparencia ayuda a mejorar y permite la comparación con otros para, entre otras cosas, detectar buenas prácticas. Algunos países han puesto en marcha sus propios programas de evaluación escolar, como el Sistema de Evaluación de la Educación Básica —SAEBde Brasil, el Sistema de Medición de Calidad de la Educación - SIMCE- de Chile, y la Evaluación Nacional de Logro Académico en Centros Escolares -ENLACE- de México (OCDE/CEPAL, 2011, pp. 111-112), y poco a poco otros países se han sumado a la implantación de evaluaciones normalizadas (Colombia, Argentina, Ecuador, Uruguay). Al mismo tiempo, existen iniciativas regionales como el Laboratorio Latinoamericano de la Evaluación de la Calidad de la Educación - LLECE - que ha gestionado tres Estudios Regionales Comparativos y Explicativos - ERCE- (primero, PERCE, 1998; 
segundo, SERCE, 2006, y tercero, TERCE, 2013); el Convenio Andrés Bello —CABcon estudios sobre logro, rendimiento y eficacia escolar, que compara resultados de distintos países de la región, así como políticas, iniciativas o las iniciativas de UNESCO (Oficina Regional de Educación para América Latina y el Caribe, OREALC/ UNESCO Santiago; Instituto Internacional de Planeamiento Educativo IPPE, sede Buenos Aires).

En España y Portugal no hay tradición en evaluaciones normalizadas, aunque la existencia de institutos de evaluación ha posibilitado que ambos países se incorporen a PISA desde sus inicios y participen en otras evaluaciones internacionales. En ambos países había pruebas finales que posibilitaban la certificación en primaria y secundaria, pero fueron eliminadas a mediados de los años setenta y se reintrodujeron nuevamente evaluaciones externas hacia el año 2000 en Portugal y en $1990^{3}$ en España (EACEA, 2010, pp. 15-21). En España el desarrollo de evaluaciones nacionales coincidió con la cesión de competencias a las comunidades autónomas y hay grandes diferencias entre las comunidades autónomas en el desarrollo de pruebas externas y la dinámica que conllevan (preparación, realización, análisis, difusión de resultados), tanto es así que los investigadores no dispusieron de datos comparables sobre logros académicos del alumnado de escuelas rurales de Andalucía, Aragón y Cataluña (Domingo, Boix y Champollion, 2012, p. 430), en tanto que sí dispusieron de los datos en Chile, Francia y Uruguay (Abós, 2014, p. 107).

Además del esfuerzo estatal, cabe indicar la incidencia en la educación latinoamericana de multitud de fundaciones privadas y otras sin ánimo de lucro (Carolina, Telefónica, Escuela Nueva, Fe y Alegría), así como de proyectos con financiación externa (Luces para Aprender, Plan Ceibal) que evidencian la gran necesidad que existe en estos países.

Mención especial requieren los esfuerzos de las administraciones educativas que mantienen un departamento o programa de educación rural para orientar actuaciones tendientes a favorecer la educación en el medio rural sobre todo en educación inicial o preescolar y primaria, con enfoques comunitarios, potenciación de la educación bilingüe y atención específica al aula multigrado. Entre estas experiencias Rivas destaca:

El Proyecto de Mejoramiento de la Educación Rural (PROMER) en Argentina, el Programa Mejoramiento de la Calidad y Equidad de la Educación (MECE) Rural en Chile, el Proyecto de Educación Rural en Colombia y el Proyecto de Educación Rural en Perú. Brasil desarrolló el Programa Nacional de Educación Rural, dirigido al acceso, permanencia y aprendizaje. El Programa Educativo Rural de México proporcionó recursos a las escuelas que brindan educación tecnológica agropecuaria, forestal y del mar (Rivas, 2015, p. 115).

\footnotetext{
3 La Ley de Ordenación General del Sistema Educativo (LOGSE, 1990) no estableció ninguna evaluación estandarizada, y fue la Ley Orgánica de Educación (LOE, 2006) la que implantó evaluaciones diagnósticas que, con mayor o menor fortuna, se han desarrollado a nivel nacional o autonómico.
} 
México además ofrece recursos a las escuelas rurales en zonas deprimidas, el desarrollo de telesecundarias para acercar esta enseñanza a la población rural con el uso de audiovisuales y tecnologías de la información y la comunicación -TIC-, y la formación inicial que se imparte a los futuros maestros rurales en las Escuelas Normales Rurales, diferenciadas del resto. En este país podemos encontrar varios estudios en distintos momentos sobre pruebas estandarizadas y ruralidad, y se destacan los artículos que analizan factores que se deben considerar en todos los estudios (Juárez y Rodríguez, 2016), la referencia a la novedad de estas investigaciones (Martínez-Rizo, 2016) o sus limitaciones (Jornet, 2016).

La Fundación Escuela Nueva de Colombia, con su dilatada trayectoria, ha contribuido al reconocimiento internacional de la escuela rural como factor de desarrollo comunitario. En países con un índice de ruralidad y unas tendencias demográficas tan dispares como Argentina, Brasil, Chile, Colombia, México, Perú o Uruguay ha habido atención por la educación rural. En cambio en Portugal y España no existe departamento educativo específico y se trata la educación rural como un apartado de la educación compensatoria. Todos ellos han hecho grandes esfuerzos en la última década por extender el uso de las TIC en el sistema educativo y especialmente entre el alumnado, como medio para subsanar algunas desigualdades educativas y reducir la inequidad urbano-rural. Pese a ello, hay temas pendientes como "entender la educación rural en su contexto, las cuestiones y diferencias territoriales o estudiar las áreas y los años de enseñanza no evaluados por PISA y TERCE” (Rivas, 2015, p. 289), potenciar redes educativas, comunidades de aprendizaje y actitud favorable a la educación a lo largo de la vida.

Merece la pena mencionar el informe Inspiraciones alcanzables: 15 políticas edcativas destacadas en América Latina, con 167 referencias a rural, y entre ellas tres propiamente rurales: Microcentros Rurales (Chile), Escuela Nueva (Colombia) y Centros Rurales de Formación en Alternancia (Perú), con abundantes propuestas que se han comprobado útiles en América Latina, así como referencias muy actualizadas (Sánchez y Coto, 2016).

Finalmente, no se puede olvidar aquí la accesibilidad a datos sobre rendimientos escolares y otros indicadores educativos vinculados a pruebas internacionales (PISA, SERCE, TERCE) que aporta el Centro de Información para la Mejora de los Aprendizajes (CIMA, 2017), dependiente del Banco Interamericano de Desarrollo (BID), que a su vez aporta una importante serie de publicaciones y documentos de trabajo sobre condiciones de la educación en América Latina.

\section{Resultados: Visión general de la educación rural en los informes PISA}

Respecto del grado de urbanización o ruralidad, PISA pregunta a los directores de escuelas qué definición describe mejor la comunidad en la que se ubica la escuela que dirigen:

a) Un pueblo, una aldea o una zona rural (menos de 3.000 personas). Lo abreviamos como R, Rural. 
b) Un pequeño pueblo (de 3.000 a 15.000 personas). Abreviado como M1, forma parte de Medio M.

c) Un pueblo (entre 15.000 y 100.000 personas). Abreviado como M2, forma parte de Medio M.

d) Una ciudad (entre 100.000 y 1.000.000 de personas). Abreviado como U1, forma parte de Urbano U.

Una gran ciudad (con más de 1.000.000 de personas). Abreviado como U2, integrado en Urbano U.

Así, para PISA "las escuelas rurales son aquellas donde el director responde a 'un pueblo, una aldea o una zona rural', mientras que las escuelas urbanas son aquellas en los que el director contestó 'una ciudad' o 'una gran ciudad"' (OCDE, 2016b, p. 56). En sus comparaciones habituales en tablas, PISA toma como referencia las ubicaciones intermedias (zonas M1 y M2, entre 3.000 y 100.000 habitantes, citados M como conjunto medio) y las compara con las rurales $\mathrm{R}$ (menos de 3.000) y las urbanas $\mathrm{U}$ (U1 y U2, más de 100.000 o más de un millón de habitantes), pero no realiza este tipo de comparación en todas las rondas, y conviene observar bien los datos de comparación en las tablas de distintas rondas sobre ruralidad, porque podemos equivocarnos. Si usamos Pisadataexplorer podemos obtener datos de comparación de las cinco ubicaciones, importantes para saber qué pasa en M1 (hasta 15.000 habitantes), puesto que en la catalogación M tienen la misma consideración los pueblos de 3.001 habitantes que las ciudades de 99.999.

En la tabla 1 se presentan estimaciones del Banco Mundial sobre porcentajes de población rural desde 2000 hasta 2015, para compararlas con las muestras de las rondas trienales de PISA.

Tabla 1. Porcentajes de población rural en distintos años en relación con las muestras PISA.

\begin{tabular}{|l|c|c|c|c|c|c|c|c|c|c|c|}
\hline \multicolumn{1}{|c|}{ Jurisdicción } & \multicolumn{5}{|c|}{ Banco Mundial } & PISA & PISA & PISA & PISA & Rivas & PISA \\
\hline & 2003 & 2006 & 2009 & 2012 & 2015 & 2003 & 2006 & 2009 & 2012 & 2013 & 2015 \\
\hline Argentina & 10,3 & 9,7 & 9,2 & 8,7 & 8,2 & & 9,7 & 8,3 & 8,5 & 9,1 & 3,4 \\
\hline Brasil & 17,8 & 16,9 & 16,0 & 15,1 & 14,3 & 8,7 & 16,7 & 4,4 & 1,1 & 15,6 & 3,0 \\
\hline Chile & 13,1 & 12,3 & 11,6 & 11,0 & 10,5 & & 12,1 & 1,5 & 3,5 & 10,0 & 1,4 \\
\hline Colombia & 27,0 & 26,1 & 25,3 & 24,4 & 23,6 & & 25,4 & 10,9 & 13,0 & 24,0 & 7,9 \\
\hline Costa Rica & 36,9 & 33,1 & 29,4 & 26,1 & 23,2 & & & & 23,5 & & 19,0 \\
\hline Rep. Dominicana & 35,4 & 31,3 & 27,5 & 24,0 & 21,0 & & & & & & 13,0 \\
\hline España & 23,2 & 22,5 & 21,8 & 21,1 & 20,4 & 4,2 & 23,2 & 4,1 & 3,3 & & 3,4 \\
\hline Unión Europea & 27,9 & 27,2 & 26,5 & 25,8 & 25,2 & & & & & & \\
\hline
\end{tabular}




\begin{tabular}{|l|c|c|c|c|c|c|c|c|c|c|c|}
\hline \multicolumn{1}{|c|}{ Jurisdicción } & \multicolumn{5}{c|}{ Banco Mundial } & PISA & PISA & PISA & PISA & Rivas & PISA \\
\hline & 2003 & 2006 & 2009 & 2012 & 2015 & 2003 & 2006 & $\mathbf{2 0 0 9}$ & $\mathbf{2 0 1 2}$ & $\mathbf{2 0 1 3}$ & $\mathbf{2 0 1 5}$ \\
\hline $\begin{array}{l}\text { América Latina y } \\
\text { Caribe }\end{array}$ & 23,7 & 22,7 & 21,8 & 20,9 & 20,1 & & & & & & \\
\hline México & 24,3 & 23,4 & 22,5 & 21,6 & 20,8 & 23,3 & & 16,1 & 15,1 & 23,5 & 10,3 \\
\hline OECD & 23,2 & 22,2 & 21,3 & 20,5 & 19,7 & 11,1 & & 9,9 & 9,4 & & 7,4 \\
\hline Perú & 25,8 & 24,6 & 23,4 & 22,4 & 21,4 & & & & 18,8 & 24 & 24,3 \\
\hline Portugal & 43,7 & 41,9 & 40,0 & 38,2 & 36,5 & 6,8 & 48,8 & 8,8 & 6,0 & & 6,1 \\
\hline Uruguay & 7,2 & 6,4 & 5,8 & 5,2 & 4,7 & 7,0 & 7,9 & 12,5 & 7,1 & 5,3 & 5,2 \\
\hline
\end{tabular}

Fuente: Elaboración propia a partir de porcentaje de población rural del Banco Mundial (2017b) y de informes sobre PISA (2003 de OECD, 2013c; 2006 de GIP, 2009; 2009 de OECD, 2011; 2012, de OCDE, 2013b; 2015 de OCDE, 2016b; Rivas, 2015)

En todas las jurisdicciones pierde peso la población rural, pero es más acelerada en Costa Rica y República Dominicana que tenían las tasas rurales más elevadas. En el entorno europeo la reducción es más exigua, y se destaca Portugal. Las estimaciones de población rural para 2015 en los países latinoamericanos que realiza el Banco Mundial son parecidas a las de otros estudios para 2013 (Rivas, 2015, p. 38).

Se han resaltado en amarillo los datos muy diferentes de PISA respecto de porcentaje rural. En 2006 las muestras de PISA y la estimación son parecidas. En cambio, en 2003, 2009, 2012 y 2015 las muestras de PISA son muy reducidas en la mayor parte de las jurisdicciones estudiadas en relación con el porcentaje de población rural estimada, con excepción de Uruguay que ofrece en las cinco rondas una muestra rural mayor que la estimada. Estos datos confirman la infraestimación de muestra rural en PISA, lo que sugiere que la muestra PISA no es representativa de las poblaciones rurales en América Latina (Rivas, 2015, p. 251).

El único dato en los informes PISA 2000 sobre diferencia urbano-rural se refiere al nivel socioeconómico y cultural (NSEC) de los centros urbanos, superior al de los centros rurales en 39 de los 40 países que miden esa brecha (OECD/UIS, 2003, p. 221). Sin embargo, el informe en español indica que la segregación escolar observada en algunos países puede deberse a la segregación residencial en grandes ciudades o a la división económica entre zonas rurales y urbanas. Además, la puntuación de los centros cuya ratio alumnado/docente es inferior a 10, en general obtienen entre 5 y 10 puntos por debajo de la media de la OCDE, posiblemente por ser escuelas de alumnado con necesidades especiales o son escuelas rurales pequeñas (OCDE, 2002, pp. 221-223). Pero no hay datos sobre rendimiento rural.

En PISA 2003 se indica que los centros de zonas rurales obtienen menor puntuación que la media de matemáticas, pero al descontar el efecto del nivel socioeconómico (NSEC) del alumnado y del centro las diferencias se reducen llegando a revertirse, y para la OCDE la media de centros rurales tiene un ventaja de 8,7. Este hecho sugiere 
que parte de la desventaja de las escuelas rurales se debe a factores socioeconómicos y no tanto a la calidad que ofrece el centro escolar (OECD, 2004, p. 260). No obstante, las diferencias rural-urbano en los distintos países son muy importantes: Estados Unidos $(19,61)$, Canadá $(8,85)$, España $(8,14)$, Portugal $(0,87)$, México $(-8,05)$, Brasil $(-11,55)$ y Corea $-19,69$, siendo estadísticamente significativas las brechas rural-urbano en Estados Unidos, Canadá y México (OECD, 2004, pp. 439-440).

El volumen I de PISA 2006 contiene siete citas a rural e indica que puede haber diferencias significativas en los niveles de desempeño entre escuelas debido a los factores socioeconómicos, a las características de las comunidades atendidas o a diferencias geográficas como las existentes entre áreas rurales y urbanas, que pueden ser reflejo de la segregación socioeconómica rural-urbana o la que se produce en las grandes ciudades (OECD, 2007, pp. 172, 196). En cambio, en el volumen II no hay ningún comentario a las diferencias de medias de ciencias entre centros de zonas rurales y urbanas, aunque en la tabla 5.21b (OECD, 2008a, p. 217), sí se indican diferencias significativas, en general en contra de los rurales. De 54 países con datos, al restar del estrato intermedio (ciudad de 15.000 a 100.000 habitantes) el factor menos de 15.000 es positivo para 36 , neutro en 1 y negativo para 17 . El factor más de 100.000 es positivo para 19, neutro en 1 y negativo para 34, lo que viene a reiterar que, descontando efectos demográficos y socioeconómicos, el factor rural -escuelas en localidades de menos de quince mil habitantes- empeora los resultados en ciencias, en tanto que el factor ciudad —escuelas en localidades de más de cien mil habitanteslo mejora (OECD, 2008b, hoja de cálculo tabla 5.21b). Otro hecho importante en esta ronda es que, una vez descontado el factor socioeconómico, se intenta ponderar el peso de distintos factores en los resultados, y se presentan varias tablas donde las diferencias entre rural-urbano en resultados de ciencias suponen mayor impacto que el género (6 puntos) o los antecedentes de inmigración (10 puntos), siendo el factor con mayor impacto utilizar en casa la misma lengua que la que se usa en las pruebas PISA (25 puntos). Lo más curioso es que estas observaciones sobre ruralidad no constan en los textos de los volúmenes publicados.

A su vez, el Informe regional Iberoamérica en PISA 2006 contiene ochenta veces la palabra rural, e indica que la caracterización de una población como urbana o rural suele hacerse con datos del número de habitantes y se olvidan circunstancias importantes como la distancia con respecto a poblaciones mayores, la existencia de vías de comunicación y transportes eficientes, o la presencia de servicios como electricidad y teléfono, que pueden variar de forma significativa aunque el tamaño de población sea similar, remarcando que la ruralidad no significa lo mismo en todos los países. Por eso, las condiciones de las escuelas de localidades rurales aisladas carentes de servicios básicos en países pobres no pueden equipararse a las de poblaciones de tamaño similar en países ricos, cuyas circunstancias son muy diferentes. La dispersión geográfica y la accesibilidad a bienes y servicios afectan los logros educativos de la población, y se deben considerar en los programas educativos rurales para asegurar grados razonables de calidad y equidad (GIP, 2009, p. 24). 
En cuanto a las comunidades autónomas en España, no se pueden relacionar resultados de PISA y ruralidad porque algunas autonomías muy rurales obtienen mejores resultados que la media (Castilla y León, Galicia), por lo que se sugieren otros factores como los procesos de aula, la organización escolar o buen trabajo de los equipos docentes, y la actitud de los alumnos y sus familias, y se concluye que los factores escolares en muchas ocasiones permiten contrarrestar los condicionantes sociales, económicos y culturales de sus alumnos y sus contextos (GIP, 2009, p. 136).

Además de analizar el perfil de cada país, se estudian distintos factores para valorar la equidad y calidad del sistema educativo, entre los que seleccionamos el efecto del aumento del NSEC en los resultados y la proporción de la varianza de los resultados explicada dentro de cada escuela (intraescolar), en comparación con la varianza entre unas escuelas y otras (interescolar).

El aumento de una unidad del NSEC en la media de ciencias es alto y significativo para Uruguay, España y Brasil (de 30 a 34 puntos). Cuanto mayor es este valor menos equitativo es el sistema educativo.

La varianza interescolar de Colombia, México, Portugal y España es inferior a la media de OCDE, en cambio la varianza intraescolar mayor se observa en España y la menor en México. Chile es el único país del GIP cuya varianza interescolar es superior a la intraescolar, lo que muestra un sistema educacional chileno inequitativo en el que la escuela a la que asiste cada estudiante influye más en su rendimiento que las diferencias dentro de cada escuela, hecho que responde a la fuerte segregación escolar que hay en ese país. En definitiva, la escuela aporta un valor añadido a cada estudiante en particular, valor añadido que puede ser positivo o negativo (GIP, 2009, pp. 177-179).

En este informe se advierten limitaciones importantes a PISA para interpretar sus resultados. Entre ellas destacamos tres: no considerar la diversidad cultural de los estudiantes porque PISA se pensó para NSEC más elevados; no contrastar los datos de cuestionarios de contexto con otras fuentes o entre los procedentes de perfiles diferentes de informadores (alumnado, profesorado, directores o familias); utilizar un modelo analítico con base en una imagen instantánea, obviando los efectos acumulativos de distintos factores a lo largo de la escolaridad y que pueden haber variado en el tiempo, como el clima escolar, el profesorado y su estabilidad, la infraestructura y la dotación material (GIP, 2009, pp. 182-183).

PISA 2009 se centró en comprensión lectora. En PISA 2009 Results: Overcoming Social Background: Equity in Learning Opportunities and Outcomes (Volume II), se comparan resultados de ubicaciones de menos de 3.000 habitantes con poblaciones entre 15.000 y 100.000 habitantes, y se reitera la brecha urbano-rural después de descontar el efecto del nivel socioeconómico en más de 45 puntos en muchos países, diferencia superior a un año académico. En algunos países la diferencia alcanza los 80 puntos, pero también se indica que hay algunos países que no presentan este patrón 
como Finlandia, Alemania o Bélgica (OECD, 2010, p. 14). Se sugiere que los alumnos de ciudad pueden disponer de bibliotecas y museos para apoyar su aprendizaje y que el alumnado rural tiene menos acceso a estos recursos, pero además del factor geográfico hay factores individuales que influyen negativamente en los resultados como el origen inmigrante, ser de familia monoparental o hablar un idioma en casa diferente al que se habla en la escuela (OECD, 2010, p. 60). No obstante, la influencia del contexto socioeconómico en zonas rurales es fuerte y algunas comunidades aisladas pueden necesitar políticas educativas específicas para asegurar que los escolares alcancen todo su potencial (OECD, 2010, p. 49), aunque ello depende de múltiples factores para considerar en el análisis de resultados, como las diferentes densidades de población y las características y distribución de las poblaciones entre diferentes tipos de comunidades (OECD, 2011, tabla II.2.6).

\section{La educación rural iberoamericana en PISA 2012}

El volumen I de resultados PISA 2012 sólo tenía 10 referencias a rural y la mitad correspondían a Brasil, país del cual se indica que hay muchas escuelas rurales multigrado en las que no se puede definir exactamente el grado escolar del alumnado, y por este motivo los resultados generales del país publicados en el libro no contemplan las escuelas rurales, cuyos datos se consideran en el anexo A7 (OECD, 2014, p. 295). Nuevamente se observa la exclusión de la ruralidad en PISA.

En el PISA 2012 Results: Excellence Through Equity: Giving Every Student the Chance to Succeed (Volume II) (OECD, 2013) encontramos 65 referencias a rural y varias tablas de datos al respecto con un apartado específico de efecto de la ubicación geográfica urbano-rural en los resultados PISA. Como resumen de brechas en PISA 2012, la diferencia media de puntuación entre dos alumnos de cursos sucesivos es de 41 puntos; los chicos superan a las chicas en matemáticas por 11 puntos; los estudiantes no inmigrantes obtienen 34 puntos más que sus pares con ascendientes inmigrantes; los favorecidos por situarse en el cuartil económico superior de su país aventajan en 90 puntos a los del cuartil inicial, desfavorecidos, y los de escuelas de ciudad consiguen 31 puntos más que los estudiantes de escuelas rurales (OECD, 2013, p. 28). En PISA 2012 la brecha urbano-rural supera con creces la brecha de género, es equivalente a la brecha de inmigración y algo inferior a un año de desfase escolar. Se afirma que las grandes ciudades o las zonas densamente pobladas tienden a ofrecer importantes ventajas a las escuelas: un ambiente cultural más rico, un lugar de trabajo más atractivo para los maestros, más opciones de elección de centro escolar y mejores perspectivas laborales que ayudan a motivar a los estudiantes, quienes, además, en caso de necesitarlo, pueden recibir asistencia para compensar sus carencias. Ello influye en los resultados e incluso después de descontar el efecto del NSEC los urbanos suelen puntuar más que los rurales, pero hay algunos países donde la ubicación intermedia es la que obtiene mejores resultados, y nuevamente se indica que en los Estados Unidos los estudiantes en las escuelas urbanas rinden menos que los de escuelas rurales pese a disfrutar de condiciones socioeconómicas mejores (OECD, 2013a, p. 69). 
Con el objetivo de poder comparar países de niveles de ingreso similares, un grupo de investigación vinculado a la OCDE elaboró el informe La experiencia de los países de ingresos medios participantes en PISA 2000-2015 (Lockheed, Prokic-Bruer y Shadrova, 2015), en el que encontramos 20 referencias a rural como evidencia de la importancia de la ruralidad en los países de ingresos medios. Aquí se han seleccionado datos de países latinoamericanos.

Tabla 2. Brechas en el rendimiento de matemáticas por las características de los estudiantes en países de ingresos medianos. PISA 2012

\begin{tabular}{|c|c|c|c|c|c|c|c|}
\hline \multirow[b]{2}{*}{ Jurisdicción } & \multicolumn{5}{|c|}{ Brechas en resultados de matemáticas PISA 2012} & \multirow[b]{2}{*}{$\begin{array}{c}\text { No } \\
\text { habla de } \\
\text { Lenguaje } \\
\text { de Prueba } \\
(\%)\end{array}$} & \multirow[b]{2}{*}{$\begin{array}{c}\text { Estatus } \\
\text { socio- } \\
\text { económico }\end{array}$} \\
\hline & $\begin{array}{l}\text { Género } \\
\text { (chico- } \\
\text { chica) }\end{array}$ & $\begin{array}{c}\text { NSEC } \\
\text { dentro } \\
\text { de la } \\
\text { escuela }\end{array}$ & $\begin{array}{c}\text { NSEC } \\
\text { entre } \\
\text { escuelas }\end{array}$ & $\begin{array}{c}\text { Lenguaje } \\
\text { en casa }\end{array}$ & $\begin{array}{c}\text { Ubicación } \\
\text { urbana- } \\
\text { rural }\end{array}$ & & \\
\hline OECD & $11^{*}$ & $19^{*}$ & $72^{*}$ & $33^{*}$ & $36^{*}$ & 10,6 & O \\
\hline Argentina & $14^{*}$ & $9^{*}$ & $49^{*}$ & $45^{*}$ & $31^{*}$ & 1,6 & $-0,72$ \\
\hline Brasil & $18^{*}$ & $8^{*}$ & $46^{*}$ & -2 & $41^{*}$ & 1,1 & $-1,17$ \\
\hline Colombia & $25^{*}$ & $11^{*}$ & $35^{*}$ & $36^{*}$ & $50^{*}$ & 0,7 & $-1,26$ \\
\hline Costa Rica & $24^{*}$ & $10^{*}$ & $34^{*}$ & -19 & $36^{*}$ & 1,2 & $-0,98$ \\
\hline México & $14^{*}$ & $5^{*}$ & $29^{*}$ & $47^{*}$ & $58^{*}$ & 3,2 & $-1,11$ \\
\hline Perú & $19^{*}$ & $10 *$ & $49^{*}$ & $76^{*}$ & $89 *$ & 6,4 & $-1,23$ \\
\hline
\end{tabular}

Fuente: Elaboración propia a partir de OCDE, 2015: Tablas 6.1. y 6.6.

* Brecha significativa $\mathrm{p}<0,01$

La brecha de puntuaciones según ubicación de la escuela oscila entre 31 puntos en Argentina y 89 puntos en Perú, equivalentes a un curso escolar y casi tres, respectivamente. Las brechas urbano-rural son mucho mayores que las de género en todas las jurisdicciones, que varían de 11 a 25 puntos. En general la brecha de puntuación de los que usan en casa la lengua de la prueba suele ser algo inferior a la brecha urbano-rural, con excepción de Argentina. Cabe destacar los casos de Brasil y Costa Rica, donde la brecha es negativa y parece que obtienen mejores resultados los que hablan una lengua diferente en casa. La brecha por lengua familiar absoluta más alta corresponde a Perú con 76 puntos, y la más baja se atribuye a Brasil con 2. Curiosamente, en el primer caso hay un alto porcentaje de población que habla lenguas diferentes del español, con mucha implantación rural, mientras que en Brasil hay un porcentaje de población que habla diversas lenguas nativas distintas del portugués, sobre todo en zonas rurales, que no fueron representadas en PISA 2012. La brecha de puntuaciones según el NSEC entre escuelas es mayor que la de ubicación en tres de las ocho jurisdicciones. La brecha de puntuaciones según NSEC dentro de la misma escuela es mucho menor que la brecha de ubicación, en todas las jurisdicciones.

La conclusión principal es que tanto en la OCDE como en los países de América Latina de ingresos medios, la brecha urbano-rural que manifiestan los resultados de PISA 
2012 en matemáticas es mayor que las otras brechas estudiadas: brecha de NSEC en el propio centro, brecha de género, brecha de NSEC entre centros y brecha lingüística.

En general en los países de ingresos medios de América Latina los alumnos urbanos obtienen mejores resultados que los rurales, con mayores diferencias que la media de la OCDE (Lockheed, Prokic-Bruer y Shadrova, 2015, pp. 88-89). Aunque este resultado ha sido constatado ampliamente por la OCDE, quizás el contexto familiar y el escolar añaden otras variables que actúan simultáneamente y podrían influir negativamente en los resultados rurales, como se deduce de los análisis multinivel realizados (hablar una lengua diferente de las pruebas, menor preescolarización, clima y nivel escolar, cantidad de repeticiones) (Lockheed, Prokic-Bruer y Shadrova, 2015, p. 94), así como menor nivel en recursos culturales, educativos y económicos de la población rural.

Abundando en el diferencial urbano-rural en las medias de matemáticas, que fue la competencia estudiada en mayor profundidad en PISA 2012, para la OCDE y países iberoamericanos, interesa destacar las brechas de NSEC por localización de la escuela y sus resultados, a partir de un resumen de la Tabla II.3.3a. Relación entre desempeño en matemáticas y localización de la escuela.

Tabla 3. Puntuación media de matemáticas por ubicación de la escuela y NSEC. PISA 2012.

\begin{tabular}{|c|c|c|c|c|c|c|c|c|c|c|c|c|c|c|c|}
\hline \multirow{2}{*}{$\begin{array}{l}\text { Jurisdic- } \\
\text { ción }\end{array}$} & \multicolumn{3}{|c|}{$\begin{array}{c}\text { \% muestra } \\
2012\end{array}$} & \multicolumn{4}{|c|}{ NSEC } & \multicolumn{3}{|c|}{$\begin{array}{c}\text { Media antes } \\
\text { A NSEC }\end{array}$} & \multicolumn{3}{|c|}{$\begin{array}{c}\text { Media } \\
\text { después D } \\
\text { NSEC }\end{array}$} & \multicolumn{2}{|c|}{$\begin{array}{c}\text { Variación } \\
\text { Media } \\
\text { U-R }\end{array}$} \\
\hline & $\mathbf{R}$ & M & $\mathbf{U}$ & $\mathbf{R}$ & M & $\mathbf{U}$ & U-R & $\mathbf{R}$ & M & $\mathbf{U}$ & $\mathbf{R}$ & M & $\mathbf{U}$ & $\begin{array}{l}\text { AN- } \\
\text { SEC }\end{array}$ & $\begin{array}{l}\text { DN- } \\
\text { SEC }\end{array}$ \\
\hline Chile & 3,5 & 38,6 & 57,9 & $-1,72$ & $-0,83$ & $-0,34$ & 1,38 & 358 & 417 & 431 & 416 & 446 & 443 & 73 & 24 \\
\hline México & 15,1 & 42,0 & 43,0 & $-2,18$ & $-1,32$ & $-0,53$ & 1,65 & 375 & 408 & 433 & 411 & 433 & 442 & 58 & 32 \\
\hline Portugal & 6,0 & 72,2 & 21,9 & $-1,14$ & $-0,55$ & $-0,08$ & 1,06 & 457 & 491 & 492 & 496 & 511 & 495 & 36 & -12 \\
\hline España & 3,3 & 58,8 & 37,9 & $-0,61$ & $-0,28$ & $-0,02$ & 0,60 & 467 & 480 & 495 & 488 & 490 & 495 & 28 & 6 \\
\hline OCDE & 9,4 & 55,9 & 34,7 & $-0,33$ & $-0,04$ & 0,15 & 0,48 & 468 & 493 & 504 & 479 & 494 & 498 & 31 & 13 \\
\hline Argentina & 8,5 & 53,9 & 37,5 & $-1,38$ & $-0,71$ & $-0,59$ & 0,79 & 369 & 386 & 400 & 406 & 404 & 415 & 31 & 9 \\
\hline Brasil & 1,1 & 49,5 & 49,3 & $-1,99$ & $-1,51$ & $-0,80$ & 1,19 & 365 & 378 & 406 & 417 & 416 & 426 & 42 & 5 \\
\hline Colombia & 13,0 & 31,4 & 55,5 & $-2,31$ & $-1,41$ & $-0,93$ & 1,38 & 339 & 371 & 389 & 392 & 406 & 411 & 50 & 17 \\
\hline
\end{tabular}




\begin{tabular}{|c|c|c|c|c|c|c|c|c|c|c|c|c|c|c|c|}
\hline \multirow{2}{*}{$\begin{array}{c}\text { Jurisdic- } \\
\text { ción }\end{array}$} & \multicolumn{3}{|c|}{$\begin{array}{c}\% \text { muestra } \\
2012\end{array}$} & \multicolumn{4}{|c|}{ NSEC } & \multicolumn{3}{|c|}{$\begin{array}{c}\text { Media antes } \\
\text { A NSEC }\end{array}$} & \multicolumn{3}{|c|}{$\begin{array}{c}\text { Media } \\
\text { después D } \\
\text { NSEC }\end{array}$} & \multicolumn{2}{|c|}{$\begin{array}{c}\text { Variación } \\
\text { Media } \\
\text { U-R }\end{array}$} \\
\hline & $\mathbf{R}$ & M & $\mathbf{U}$ & $\mathbf{R}$ & M & $\mathbf{U}$ & U-R & $\mathbf{R}$ & M & $\mathbf{U}$ & $\mathbf{R}$ & M & $\mathrm{U}$ & $\begin{array}{l}\text { AN- } \\
\text { SEC }\end{array}$ & $\begin{array}{l}\text { DN- } \\
\text { SEC }\end{array}$ \\
\hline Costa Rica & 23,5 & 61,7 & 14,8 & $-1,55$ & $-0,87$ & $-0,52$ & 1,04 & 388 & 411 & 424 & 425 & 431 & 436 & 35 & 12 \\
\hline Perú & 18,8 & 40,4 & 40,9 & $-2,13$ & $-1,42$ & $-0,64$ & 1,49 & 313 & 359 & 402 & 375 & 406 & 420 & 89 & 50 \\
\hline Uruguay & 7,1 & 56,5 & 36,4 & $-1,43$ & $-1,08$ & $-0,47$ & 0,96 & 365 & 397 & 439 & 417 & 436 & 455 & 74 & 35 \\
\hline
\end{tabular}

Fuente: Elaboración propia a partir de OCDE (2013b), Tabla II.3.3a.

En negrita se marca la diferencia significativa antes y después de descontar el efecto del nivel socioeconómico y cultural.

Se observan tendencias que se repiten en todas las jurisdicciones:

a) Cuanto más rural es una escuela menor nivel socioeconómico presenta.

b) Todos los países iberoamericanos presentan NSEC inferior a la OCDE en todos los ámbitos, aunque las mayores diferencias se encuentran en el ámbito rural (-2,31 de Colombia frente a $-0,33$ de OCDE).

c) Las brechas de NSEC urbano-rural oscilan entre 0,48 de la OCDE y 1,65 de México.

d) Las medias de matemáticas aumentan con el grado de urbanización en todos los países.

e) Al descontar el efecto del NSEC la tendencia se suaviza, y en cuatro países puntúan más los rurales que los medios (marcado en amarillo), pero en general siguen puntuando menos los rurales que el resto.

f) La brecha U-R de matemáticas oscila entre los 89 puntos de Perú y 28 de España.

g) Al descontar el efecto del NSEC la brecha se reduce significativamente en todos los países, revirtiéndose en Portugal (-12) frente a Perú con 50 puntos.

h) La correlación entre cada muestra por jurisdicción y su NSEC es de 0,884 para rural, o,875 para zona media y 0,959 para urbana, lo que podría sugerir una mejor adaptación del cuestionario de NSEC para el ámbito urbano, seguido de rural y, en último término, medio (recordemos que esta localización representa pueblos de más de 3.000 habitantes y menos de 100.000) con una gran variabilidad. 
Estos datos evidencian distintas ruralidades en América Latina, que son diferentes también de la media OCDE y de España y Portugal.

\section{La educación rural iberoamericana en PISA 2015}

Con todos estos antecedentes, un estudioso de la escuela rural esperaba encontrar en los primeros informes PISA 2015 referencias a la brecha urbano-rural cuando se trata la equidad, tanto en la OCDE como los países del Grupo Iberoamericano PISA. Sin embargo no ha sido así, como veremos a continuación.

Los resultados de esta última ronda de PISA se liberaron el 6 de diciembre de 2016 y a partir de entonces hemos estado viendo múltiples discusiones sobre ellos en los medios de comunicación. Hasta junio de 2017 se han publicado cuatro volúmenes de resultados, de los cinco previstos.

Sorprende que en el Volumen I de Resultados PISA 2015 Excelencia y equidad en la educación, en sus 516 páginas sólo haya una cita rural (OCDE, 2016a, p. 220) sobre la Unesco, para indicar las dificultades de acceso de estudiantes rurales a la educación secundaria, publicación que contiene 167 referencias a rural (Unesco, 2015). Estas mismas dificultades se indican en la Unión Europea (Budginaitė, Siarova, Sternadel, Mackonytė y Spurga, 2016, pp. 35-36; Santamaría, 2015c). El volumen sobre equidad no contiene ninguna referencia a diferencial urbano-rural en competencias medidas en PISA, mientras sí analiza la influencia de factores como género, inmigración o nivel socioeconómico.

Si comparamos la presencia de rural en los volúmenes sobre igualdad y equidad en las dos últimas rondas PISA, se muestra la invisibilización de lo rural como factor de desigualdad en los resultados de PISA en 2015, una cita en 2015 frente a 65 en 2012, invisibilización reiterada por la Comisión Europea en un primer análisis de los resultados PISA 2015, en el que considera el género, la condición de inmigrante y el NSEC como factores que afectan la desigualdad en los resultados de PISA, obviando el grado de ruralidad o urbanización (European Comission, 2016).

Pese a la invisibilización de lo rural, podemos obtener datos mediante la aplicación en línea Pisadataexplorer sobre las puntuaciones medias en distintas competencias. En la tabla 4 ofrecemos las medias de competencia científica, porque sobre ella se focalizaron las rondas PISA de 2006 y 2015. 
Tabla 4. Puntuación en ciencias según ubicación de la escuela en PISA 2006 y PISA 2015.

\begin{tabular}{|l|c|c|c|c|c|c|c|c|c|c|}
\hline & \multicolumn{2}{|c|}{ R1 } & \multicolumn{2}{c|}{ M1 } & \multicolumn{2}{c|}{ M2 } & \multicolumn{2}{c|}{ U1 } & \multicolumn{2}{c|}{ U2 } \\
\hline & $\mathbf{2 0 0 6}$ & $\mathbf{2 0 1 5}$ & $\mathbf{2 0 0 6}$ & $\mathbf{2 0 1 5}$ & $\mathbf{2 0 0 6}$ & $\mathbf{2 0 1 5}$ & $\mathbf{2 0 0 6}$ & $\mathbf{2 0 1 5}$ & $\mathbf{2 0 0 6}$ & $\mathbf{2 0 1 5}$ \\
\hline OCDE & 474 & 471 & 490 & 483 & 498 & 493 & 506 & 503 & 505 & 501 \\
\hline Chile & 338 & 407 & 402 & 406 & 423 & 439 & 451 & 454 & 462 & 465 \\
\hline México & 355 & 374 & 377 & 405 & 414 & 420 & 435 & 427 & 439 & 439 \\
\hline Portugal & 449 & 449 & 463 & 483 & 478 & 503 & 495 & 528 & 492 & 529 \\
\hline España & 494 & 500 & 479 & 487 & 482 & 489 & 497 & 496 & 506 & 510 \\
\hline Brasil & 328 & 360 & 380 & 375 & 388 & 397 & 407 & 418 & 411 & 419 \\
\hline Colombia & 349 & 395 & 373 & 393 & 389 & 414 & 402 & 423 & 401 & 440 \\
\hline Uruguay & 385 & 407 & 426 & 427 & 424 & 424 & 417 & 433 & 445 & 461 \\
\hline
\end{tabular}

Fuente: Elaboración propia a partir de OCDE, 2017: pisadataexplorer. Medias de PISA según localización de la escuela [SCoO2301], por países en 2015-2006

Los datos muestran una mejora de resultados en todos los ámbitos y jurisdicciones excepto OCDE que reduce sus medias, pero al centrarnos en los datos de 2015, vemos en la Figura 1 dos bandas de resultados: la superior con OCDE, España y Portugal, con dinámicas diferentes, y la inferior con los países latinoamericanos y una tendencia de mejora de resultados a medida que disminuye la ruralidad.

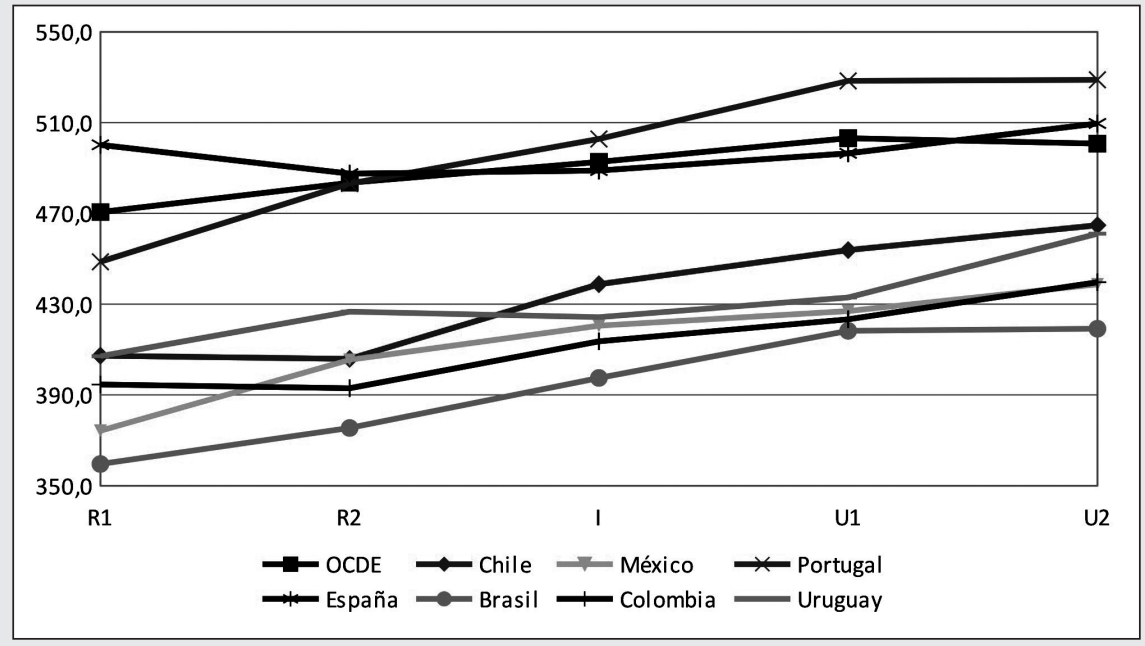

Figura 1. Resultados en ciencias según grado de ruralidad Fuente: Elaboración propia a partir de la tabla 4. 
El interés por la educación rural conlleva profundizar en el estudio de las brechas entre las zonas rurales y las más urbanas, así como su evolución en el tiempo, como se aprecia en la tabla 5 .

La valoración de los datos brutos de variación de brechas es complicada, porque no hay una tendencia generalizada clara en las distintas jurisdicciones, por este motivo presentamos casos diferentes:

- La OCDE en todas las ubicaciones ha empeorado levemente sus resultados y apenas ha reducido las brechas entre los más urbanos y los rurales (31 y 30 puntos equivalentes a 1 curso) con una variación de brecha final de -1. Casi no ha reducido la brecha con el tiempo.

- España ha mejorado levemente en todas las ubicaciones, con unas brechas U2-R bajas (12 y 9) y una variación final de -3.

- Uruguay ha mejorado en casi todas las ubicaciones, sus brechas U2-R son altas (60 y 54, equivalentes a dos cursos) y una variación final de -6.

- Colombia es el país que más ha mejorado en todas las ubicaciones, especialmente en la rural, y ha reducido sus brechas ( 52 a 45) con una variación de -7 .

- - Brasil y México presentan similitudes: han mejorado en casi todas las ubicaciones, principalmente en las menos pobladas, sus brechas U2-R superaban los 80 y han bajado a 60 , con un saldo final de -23 y -19 , respectivamente.

- Chile es el país que ha mejorado más sus resultados en rural y no mucho en otras ubicaciones, y ha reducido sensiblemente la brecha U2-R más exagerada (123 y 57) con una diferencia final de -66 . Ha reducido mucho la brecha urbano-rural.

- Portugal presenta una mejoría creciente a medida que aumenta la urbanización excepto en la rural que no mejora, la brecha U2-R era media y se ha elevado mucho (43 y 80) y la diferencia final ha supuesto un aumento de la brecha de 37 puntos, siendo el único que ha aumentado con el tiempo la brecha urbano-rural mientras aumentaba los resultados generales.

Tabla 5. Variación de la brecha urbano-rural de resultados de ciencias en PISA 2015-2006

\begin{tabular}{|l|c|c|c|c|c|c|c|c|}
\hline & \multicolumn{5}{|c|}{ Variación de medias 2015-2006 } & \multicolumn{2}{c|}{ Brecha U2-R } & $\begin{array}{c}\text { Variación } \\
\text { de brecha }\end{array}$ \\
\hline & R & M1 & M2 & U1 & U2 & $\mathbf{2 0 0 6}$ & $\mathbf{2 0 1 5}$ & $\mathbf{2 0 1 5}-2006$ \\
\hline OCDE & -4 & -6 & -6 & -3 & -4 & 31 & 30 & -1 \\
\hline Chile & 69 & 4 & 15 & 3 & 3 & 123 & 57 & -66 \\
\hline México & 19 & 28 & 7 & -8 & 0 & 84 & 65 & -19 \\
\hline Portugal & 0 & 20 & 25 & 34 & 37 & 43 & 80 & 37 \\
\hline España & 6 & 8 & 7 & 0 & 3 & 12 & 9 & -3 \\
\hline Brasil & 32 & -5 & 10 & 11 & 9 & 83 & 60 & -23 \\
\hline Colombia & 46 & 20 & 25 & 21 & 39 & 52 & 45 & -7 \\
\hline Uruguay & 22 & 1 & 0 & 16 & 16 & 60 & 54 & -6 \\
\hline
\end{tabular}

Fuente: Elaboración propia. 
Vistos estos resultados, se sugiere estudiar con profundidad qué ha hecho cada país en función de los objetivos. Si se pretende mejorar bien en todas las ubicaciones sin abandonar la rural hay que estudiar Colombia, pero si pretendemos mejorar en general abandonando la rural conviene estudiar Portugal. En cambio, si pretendemos mejorar sobre todo la rural hay que estudiar Chile, México y Brasil. Todos los países latinoamericanos presentan mejoras en rural y reducen la brecha frente a la OCDE y España, donde las mejoras en estos 9 años han sido exiguas, por lo cual aportamos más datos de los países latinoamericanos.

Tabla 6. Brechas de puntuación media en ciencias por género, lengua, preescolar, NSEC y ubicación. PISA 2015.

\begin{tabular}{|c|c|c|c|c|c|c|c|c|c|}
\hline & 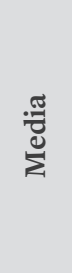 & 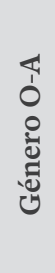 & 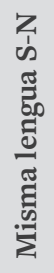 & 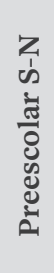 & 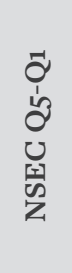 & 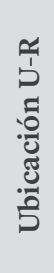 & 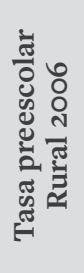 & 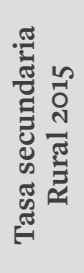 & 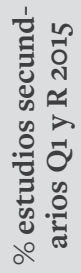 \\
\hline Brasil & 401 & 4 & 24 & 3 & 92 & 46 & 50 & 82 & 29 \\
\hline Chile & 447 & 15 & 31 & 41 & 102 & 41 & 56 & 94 & 72 \\
\hline Colombia & 416 & 10 & 23 & 8 & 86 & 28 & 47 & 71 & 58 \\
\hline Costa Rica & 420 & 18 & 9 & 6 & 78 & 12 & 41 & 83 & 69 \\
\hline México & 416 & 8 & 64 & 15 & 67 & 50 & 93 & 61 & 63 \\
\hline Perú & 397 & 10 & 67 & 38 & 104 & 48 & 59 & 79 & 58 \\
\hline Rep. Dominicana & 332 & 2 & 15 & 11 & 74 & 37 & 69 & 87 & 43 \\
\hline Uruguay & 435 & 9 & 42 & 16 & 96 & 30 & 65 & 74 & s.d \\
\hline ALC & 410 & 6 & 35 & 17 & 87 & 37 & 57 & s.d & \\
\hline OCDE & 493 & 4 & 52 & 37 & 96 & 23 & & & \\
\hline Fuente & \multicolumn{8}{|c|}{ CIMA, 2017.} & $\begin{array}{l}\text { BID } \\
2015\end{array}$ \\
\hline
\end{tabular}

Fuente: Elaboración propia a partir de CIMA (2017) y BID (2015). El nivel de estudios secundarios en la población de 25-49 años NSEC 1 y Rural proviene de BID, 2015: https://ata.iadb.org/ViewIndicator/ ViewIndicator?languageId=es\&typeOfUrl=C\&indicatorId=1976 Los datos en negrita son de 2014, por no constar los de 2015.

En esta tabla de brechas resulta evidente que en todas las jurisdicciones la brecha provocada por el NSEC entre los quintiles 5 y 1 es la más importante y oscila entre 67 puntos de México y 104 de Perú (2 o 3 cursos), en tanto que la media OCDE es de 96. 
La segunda brecha en importancia es la geográfica (U-R), siempre menor que la indicada en la tabla 5, porque allí se comparaba U2-R y no todo el urbano (U1+U2). Esta brecha oscila entre 12 puntos en Costa Rica y 50 en México, en tanto que en la OCDE es de 23.

En general, la tercera brecha en importancia es la lingüística. Si los alumnos tienen como lengua habitual la de la prueba obtienen mejores resultados que si tienen una lengua propia distinta (nativos, inmigrantes). Varía entre los países, desde 9 puntos en Costa Rica hasta 67 en Perú, con 52 para la OCDE. En México, Perú, Uruguay y la OCDE esta brecha es superior a la urbano-rural.

La brecha entre los que cursaron al menos 1 año de preescolar y los que no es, en casi todas las jurisdicciones, más fuerte que la brecha de género (chico-chica), y en la OCDE la primera es de 37 puntos y la segunda, de 4.

Respecto de Latinoamérica rural, la cohorte que cursó preescolar en 2005 es la que hizo la prueba en 2015 y no se aprecia una relación con la media.

Tampoco se encuentra relación entre nivel de estudios de la población rural de bajo NSEC y las medias de cada país. Sin embargo, parece percibirse un importante avance en la escolarización secundaria de la población rural, a la vista de las tasas de escolarización comparadas con las del nivel de estudios, al menos de secundaria, de la población rural de 25-49 años, que son en su mayoría los padres de los alumnos rurales que participaron en PISA 2015.

Todos estas brechas pueden influir conjuntamente en los logros de estudiantes en PISA y habría que analizar el impacto acumulado de ellos para valorar en la justa medida el impacto de la escuela rural en los logros de su alumnado, y así poder mejorarlos y aproximarnos a sistemas educativos más equitativos, pero hasta ahora no ha habido informes PISA en base a datos de 2015 que lo evidencien y estudien en profundidad, pese a la evidencia de una brecha urbano-rural más fuerte que otras analizadas.

La excepción a estos "olvidos" ha sido la reciente publicación del Centro para la Investigación Educativa y la Innovación de la OCDE Trends Shaping Education Spotlight 9. Country Roads: Education and Rural Life (CERI, 2017). En esta breve publicación se indica que es necesario proporcionar acceso a una educación de calidad en las zonas rurales para satisfacer las necesidades de la juventud rural y posibilitar la llegada de familias jóvenes, porque si no se logra este objetivo y se mantienen las brechas urbano-rural estas zonas no rompen el círculo vicioso: falta de masa crítica para los servicios, menor nivel educativo, trabajos poco cualificados, emigración y envejecimiento demográfico y baja densidad de población. Los resultados rurales en PISA 2015 son inferiores a los de zonas urbanas en 31 puntos, casi un curso escolar, incluso después de descontar el efecto del nivel socioeconómico (CERI, 2017, p. 2), pero hay otros factores que persisten como mayor pobreza, menor preescolarización, 
dificultad de acceso a las TIC y con profesorado generalmente menos cualificado (CERI, 2017, p. 4). No obstante, también ofrece aspectos positivos: las escuelas rurales más pequeñas pueden facilitar un clima de mayor cooperación y sentido de pertenencia a la escuela, sus profesores apoyan a los estudiantes en su aprendizaje con más frecuencia que los profesores de las escuelas urbanas, suele haber mejor clima escolar y mayor preocupación de los docentes por su interacción con el alumnado, las escuelas multigrado pueden aportar ventajas a la formación, hay mejor adquisición de competencias en cursos iniciales así como competencias no cognitivas importantes (Ares, 2014). Este documento es uno de los pocos ejemplos de la OCDE que intenta exponer aspectos positivos de la escuela rural, o no verlos como negativos por ser diferentes de la educación dominante en las zonas urbanas.

Posteriormente, el informe Políticas y prácticas para escuelas exitosas (PISA 2015, Vol. II OECD, 2016-b) contiene la palabra rural 147 veces, puesto que permite obtener datos de las encuestas de contexto de estudiantes, profesorado y directores sobre sus opiniones en relación con las ciencias, competencia principal de esta ronda. Así se puede acceder a unas 25 tablas de datos que comparan resultados de opiniones de la ubicación R1 (<3.000 hab.) con M (muestra de referencia) y U (> 100.000 hab.). Los factores por estudiar son diversos: clima del aula, del centro, retrasos y faltas de asistencia, actitud hacia las ciencias, percepciones sobre atención del profesorado al alumnado, dotación del centro y muchos más. Su análisis detallado puede contribuir a definir la opinión diferencial rural/urbano sobre la enseñanza de las ciencias y su contexto, pero no aporta datos sobre los resultados del alumnado rural en PISA 2015.

A modo de ejemplo, en la tabla 7 presentamos la selección de algunas opiniones para las jurisdicciones España y OCDE, proporcionando la media general, la puntuación media del cuartil 1 del NSEC (C1), la brecha del NSEC entre el Cuartil 4 y el Cuartil 1 (C4-C1), la brecha entre escuelas privadas y públicas y, finalmente, las medias por ubicación de escuela con su error típico, así como la brecha urbano-rural en cada opinión. Hemos seleccionado cuatro ítems relacionados con opiniones del alumnado respecto de las interacciones del profesorado con el alumnado en la enseñanza de las ciencias. 
Tabla 7. Opiniones sobre la enseñanza de las ciencias en PISA 2015 según ubicación de la escuela

\begin{tabular}{|c|c|c|c|c|c|c|c|c|c|c|c|c|c|c|}
\hline \multirow{3}{*}{$\begin{array}{c}\text { Ítem sobre el } \\
\text { que opinan }\end{array}$} & \multirow{3}{*}{ 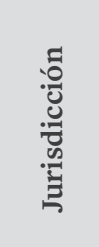 } & \multirow{2}{*}{\multicolumn{2}{|c|}{ Media }} & \multicolumn{2}{|c|}{ ESEC } & \multirow{3}{*}{$\begin{array}{l}\text { Pr- } \\
\text { Pu } \\
\text { Dif. }\end{array}$} & \multicolumn{8}{|c|}{ Ubicación de la escuela } \\
\hline & & & & Q1 & $\begin{array}{l}\text { Q4- } \\
\text { Q1 }\end{array}$ & & \multicolumn{2}{|c|}{$\begin{array}{c}<3.000 \\
(\mathbf{R 1})\end{array}$} & \multicolumn{2}{|c|}{$<100.000$} & \multicolumn{2}{|c|}{$\begin{array}{c}>100.000 \\
U\end{array}$} & \multicolumn{2}{|c|}{$\mathbf{U}-\mathbf{R} \mathbf{1}$} \\
\hline & & Índ. & S.E. & Índ. & Dif. & & Índ. & S.E. & Índ. & S.E. & Índ. & S.E. & Dif. & S.E. \\
\hline \multirow{2}{*}{$\begin{array}{l}\text { 1)Instrucción } \\
\text { dirigida por el } \\
\text { maestro }\end{array}$} & España & 4,33 & $(0,08)$ & 3,83 & 0,91 & 0,68 & 3,03 & $(0,53)$ & 4,37 & $(0,16)$ & 4,41 & $(0,25)$ & 1,38 & $(0,60)$ \\
\hline & OCDE & 4,58 & $(0,01)$ & 4,01 & 1,12 & 0,38 & 4,09 & $(0,08)$ & 4,58 & $(0,03)$ & 4,70 & $(0,04)$ & 0,60 & $(0,09)$ \\
\hline \multirow{2}{*}{$\begin{array}{l}\text { 2) Percepción } \\
\text { de retroali- } \\
\text { mentación de } \\
\text { profesores }\end{array}$} & España & 0,13 & $(0,01)$ & 0,29 & $-0,25$ & 0,05 & 0,39 & $(0,10)$ & 0,13 & $(0,02)$ & 0,10 & $(0,04)$ & $-0,28$ & $(0,11)$ \\
\hline & OCDE & $-0,01$ & $(0, \infty 0)$ & 0,16 & $-0,31$ & 0,00 & 0,14 & $(0,02)$ & ०,०० & $(0,01)$ & $-0,05$ & $(0,01)$ & $-0,18$ & $(0,02)$ \\
\hline \multirow{2}{*}{$\begin{array}{l}\text { 3)Instrucción } \\
\text { adaptativa en } \\
\text { las lecciones }\end{array}$} & España & 0,15 & $(0,01)$ & 0,22 & $-0,14$ & 0,04 & 0,34 & $(0,15)$ & 0,15 & $(0,03)$ & 0,13 & $(0,03)$ & $-0,21$ & $(0,15)$ \\
\hline & OCDE & 0,01 & $(0, \infty 0)$ & 0,01 & 0,02 & 0,10 & 0,06 & $(0,02)$ & 0,01 & $(0,01)$ & ০,০০ & $(0,01)$ & $-0,05$ & $(0,02)$ \\
\hline \multirow{2}{*}{$\begin{array}{l}\text { 4) Instrucción } \\
\text { basada en la } \\
\text { indagación }\end{array}$} & España & $-0,25$ & $(0,02)$ & $-0,26$ & $-0,02$ & 0,04 & $-0,19$ & $(0,11)$ & $-0,22$ & $(0,03)$ & $-0,29$ & $(0,03)$ & $-0,10$ & $(0,11)$ \\
\hline & OCDE & 0,00 & $(0,00)$ & 0,04 & $-0,05$ & 0,01 & 0,11 & $(0,02)$ & 0,01 & $(0,01)$ & $-0,02$ & $(0,01)$ & $-0,09$ & $(0,02)$ \\
\hline
\end{tabular}

Fuente: Elaboración propia a partir de OCDE (2016c): PISA 2015-II. Anexo B1: cómo las escuelas contribuyen a los logros y predisposición hacia las ciencias. Tablas II.2.17, II.2.2O; II.2.23; II.2.27

La comparación de los errores típicos de las distintas ubicaciones va reduciéndose conforme aumenta el tamaño de la población, y las diferencias de errores son mucho más patentes entre rural y urbano en España que en la OCDE, porque aquí las muestras rurales son muy reducidas, lo que aumenta la probabilidad de error y este hecho sugiere tomar con cierta cautela los resultados. Algunas evidencias al respecto:

1. El alumnado de escuelas rurales considera que su instrucción en ciencias está menos dirigida por los maestros que en zonas urbanas. La diferencia es mucho mayor en España que en OCDE. Las puntuaciones de OCDE son siempre mayores que en España y hay gran diferencia entre los rurales de ambas jurisdicciones. Los alumnos de escuelas en pueblos R1 provienen de pueblos pequeños, y en España los institutos en estas zonas suelen tener entre 40-200 alumnos en 
total, lo que permite una mayor interacción del profesorado con el alumnado y educación más personalizada basada en la experiencia del alumnado procedente de escuelas rurales, cuya premisa básica es el fomento de la autonomía y la responsabilidad del alumnado en su aprendizaje. Este hecho podría mediatizar que los alumnos rurales indiquen que sus profesores los dirigen menos que en zonas urbanas. En España la diferencia geográfica en los dos ámbitos es mayor que la diferencia entre cuartiles extremos o entre privada-pública.

2. En zonas rurales el alumnado percibe en su profesorado una mayor retroalimentación que en zonas urbanas. Esta percepción es mucho más fuerte en España que en OCDE. El profesorado de escuelas rurales está más atento a las demandas del alumnado que en zonas urbanas, por las interacciones más personalizadas en este tipo de centros.

3 .

4. El alumnado de zonas rurales cree que sus profesores adaptan mejor las actividades que en zonas urbanas, siendo mucho mayor la diferencia en España que en OCDE, y los alumnos españoles tienen mejor percepción en cada zona que los de OCDE. Estos resultados refuerzan los anteriores.

5. Cuando se pregunta sobre la enseñanza basada en la indagación, los alumnos rurales de OCDE y España consideran que practican más la indagación que los urbanos. No obstante, los alumnos de OCDE puntúan sobre o y los alumnos de España puntúan en negativo. Estos datos nos sugieren que en los centros de secundaria de España los alumnos afirman investigar menos que en la OCDE, pero los rurales investigan más que los urbanos.

Estos datos evidencian las opiniones diferentes de los rurales y los urbanos sobre metodología en clases de ciencias, que habría que explorar con mayor profundidad. No obstante, y con las reservas indicadas al principio, hay que destacar aspectos positivos para las escuelas rurales de PISA cuyos alumnos perciben que sus profesores de ciencias son menos directivos en sus clases, son más receptivos en las interacciones y hacen clases más adaptadas a sus necesidades. Todas estas características "diferenciales" de las escuelas rurales son reiteradas por maestros e investigadores y contribuyen a una educación personalizada, que en zonas rurales parece más factible (Santamaría, 2015a; CERI, 2017).

A su vez, desde el punto de vista de la enseñanza de las ciencias, cabe destacar la percepción del alumnado que considera no realizar indagaciones, incluso en zonas rurales donde es más fácil practicar el método científico y la observación directa del medio y la interacción con él. Este hecho podría entroncar en lo más profundo de la formación inicial y continua del profesorado de ciencias en España, posiblemente poco práctica y discordante con la aplicación del método científico y el fomento de la duda, la innovación y la creatividad. O quizás hay una rigidez excesiva en la organización de los centros de secundaria españoles que coarta al profesorado en el fomento de investigaciones por parte del alumnado, y no atiende la interacción con el medio como factor de investigación básico de la educación ambiental. 
El volumen III de resultados PISA 2015, El bienestar de los estudiantes, cita la palabra rural 14 veces, en relación con varios temas: las inferiores expectativas de los rurales de estudiar un grado universitario (OECD, 2017a, p. 106) y la segregación escolar por motivos económicos, tipo de estudios o por la ruralidad, y pone como ejemplos de países segregadores a Chile, Ciudad Autónoma de Buenos Aires, Perú y los Estados Unidos de América (OECD, 2017a, pp. 177-178). En ambos casos la explotación de los datos es muy superficial, como no puede ser de otra manera en informes genéricos. No obstante, el texto ha pasado por alto los datos diferenciales sobre frecuencia e índice de acoso escolar que no se comentan. En 8 de las 11 jurisdicciones estudiadas es más alto en zonas rurales que en las más urbanas, aunque son las zonas intermedias (entre 3.000 y 100.000 habitantes) de 6 jurisdicciones las que suelen presentar índices más elevados. En la tabla 8 se presentan algunos datos.

Tabla 8. Índice de exposición al acoso según tipología de la escuela, frecuencia y ruralidad.

\begin{tabular}{|c|c|c|c|c|c|c|c|c|c|c|}
\hline \multirow{4}{*}{ Jurisdicciones } & \multirow{3}{*}{$\begin{array}{l}\text { Índice } \\
\text { acoso } \\
\text { media }\end{array}$} & \multirow{3}{*}{$\begin{array}{c}\text { Frec. } \\
\text { acoso }\end{array}$} & \multirow{3}{*}{\begin{tabular}{|c}
$\begin{array}{c}\text { Po- } \\
\text { blación } \\
\text { rural }\end{array}$ \\
\\
\end{tabular}} & \multicolumn{7}{|c|}{ Índice acoso } \\
\hline & & & & \multicolumn{2}{|c|}{ Según ISEC } & \multirow{2}{*}{$\begin{array}{l}\text { Priv.- } \\
\text { Púb. }\end{array}$} & \multicolumn{4}{|c|}{$\begin{array}{l}\text { Según ubicación } \\
\text { de la escuela }\end{array}$} \\
\hline & & & & C1 & $\begin{array}{c}\mathrm{C}_{4}- \\
\mathrm{C} 1\end{array}$ & & $<3.000$ & $<100.000$ & $>100.000$ & $\mathbf{U}-\mathbf{R}$ \\
\hline & a & b & c & d & e & f & g & h & i & $\mathbf{j}$ \\
\hline Chile & 0,15 & 7,9 & 10,5 & 0,20 & $-0,06$ & $-0,04$ & 0,51 & 0,15 & 0,13 & $-0,38$ \\
\hline México & 0,13 & 10,1 & 20,8 & 0,21 & $-0,14$ & 0,02 & 0,23 & 0,03 & 0,08 & $-0,15$ \\
\hline Portugal & $-0,52$ & 5,7 & 36,5 & $-0,47$ & $-0,11$ & 0,03 & $-0,17$ & 0,11 & $-0,52$ & $-0,35$ \\
\hline España & $-0,09$ & 6,0 & 20,4 & $-0,06$ & $-0,01$ & 0,09 & $-0,06$ & 0,07 & $-0,08$ & $-0,02$ \\
\hline OCDE media & ০,০০ & 8,9 & 19,7 & 0,06 & $-0,10$ & 0,01 & 0,19 & O,০1 & $-0,03$ & $-0,14$ \\
\hline Brasil & $-0,23$ & 9,0 & 14,3 & $-0,20$ & ০,০০ & 0,05 & $-0,17$ & 0,10 & $-0,26$ & $-0,09$ \\
\hline Colombia & 0,16 & 7,6 & 23,6 & 0,17 & $-0,06$ & $-0,08$ & 0,25 & ०,०4 & 0,11 & $-0,14$ \\
\hline Costa Rica & 0,10 & 10,9 & 23,2 & 0,14 & 0,03 & $-0,02$ & 0,10 & 0,03 & 0,17 & 0,07 \\
\hline Rep. Dominicana & $-0,29$ & 12,2 & 21,0 & $-0,25$ & $-0,02$ & 0,10 & $-0,32$ & 0,10 & $-0,30$ & 0,02 \\
\hline
\end{tabular}




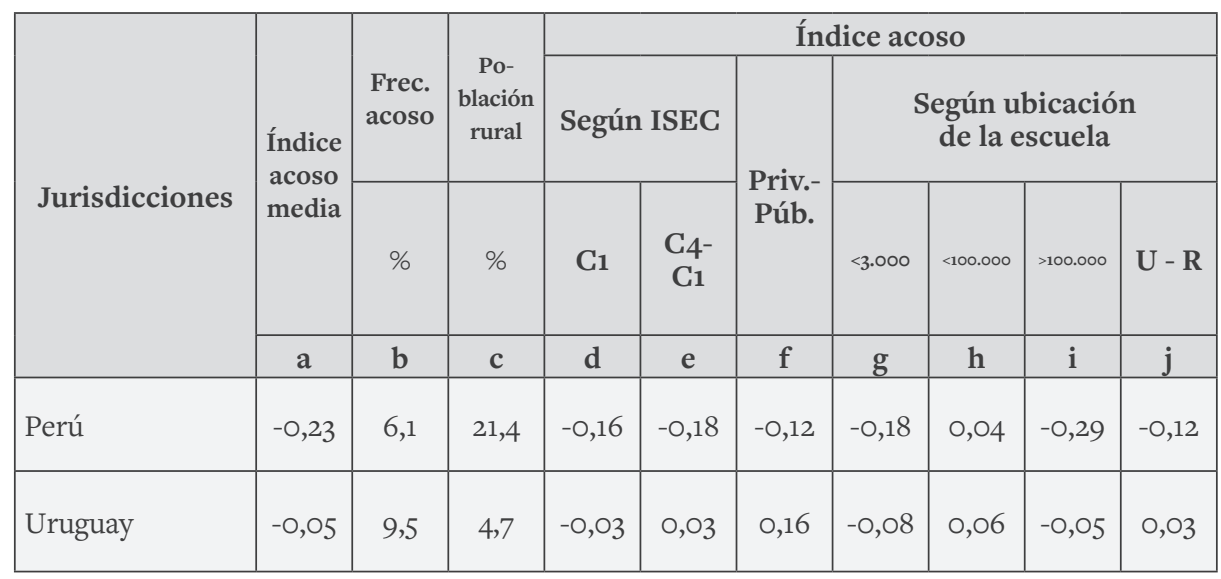

Fuente: Elaboración propia a partir de OCDE (2017 ${ }^{\mathrm{a}}$ ): tablas 3.8.1. y 3.8.6, y Banco Mundial (2017): ruralidad. Se han marcado en negrita los casos en que esta diferencia es estadísticamente significativa, con fondo amarillo el máximo y en cursiva y fondo amarillo el mínimo de cada columna.

Se podría considerar factores que contribuyen a este resultado los mismos que se atribuyen a la victimización de los inmigrantes: diferencias en el idioma, la cultura, la etnia y la apariencia (OECD, 2017a, p. 136), que en ocasiones se presentan en la población rural: nativos e indígenas, marginados en su propio territorio y oprimidos por la sociedad general, más urbana (Santamaría, 1996, pp. 113-115), y en situación clara de desventaja respecto del resto (Díaz-Aguado, Martínez y Martín, 2013, p. 354). Curiosamente, estos resultados chocan con la percepción de los docentes latinoamericanos de una escuela rural con mejor clima y más inclusiva que la escuela urbana en el TERCE (Weinstein, 2016, pp. 105-106) o con las opiniones del alumnado latinoamericano en el SERCE, donde se concluye que en zonas rurales hay menos agresividad y acoso escolar que en zonas urbanas (Román y Murillo, 2011, p. 51).

El cuarto volumen de PISA 2015 sobre competencias financieras de los estudiantes analiza este factor para 15 países participantes, entre los que se encuentran Brasil, Chile, España, Estados Unidos y Perú. Se indica que uno de los factores que pueden influir en los resultados es la ubicación del centro educativo, y se concluye que en los países con una población rural superior al $5 \%$ los alumnos más rurales obtienen peores resultados y que, en general, las escuelas de ciudad obtienen mejores resultados que las de zona rural, incluso si se computa el efecto del NSEC (OECD, 2017b, p. 100). No obstante, hay dos excepciones: en Estados Unidos la diferencia favorece a los rurales en 30 puntos (antes y después de descontar el ISEC) y en España la diferencia urbanorural es -15, pero si descontamos el ISEC se amplía a -29. Estas dos excepciones han pasado casi inadvertidas a los redactores del informe. Si nos centramos en los países iberoamericanos que realizaron la prueba financiera, los datos generales previos se indican en la tabla 9. 
Tabla 9. Ruralidad, muestra, media y error estándar por ubicación.

\begin{tabular}{|c|c|c|c|c|c|c|c|c|c|c|c|}
\hline & \multirow[b]{2}{*}{ 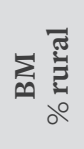 } & \multirow[b]{2}{*}{$\begin{array}{l}\stackrel{\pi}{\tilde{J}} \\
\sum \\
\sum\end{array}$} & \multicolumn{3}{|c|}{$<3000$ : rural R } & \multicolumn{3}{|c|}{ 3000-100000: M } & \multicolumn{3}{|c|}{ +100000: U } \\
\hline & & & $\%$ & $\frac{\pi}{\stackrel{\pi}{\pi}}$ & E.E. & $\%$ & 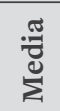 & E.E. & $\%$ & 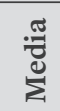 & E.E. \\
\hline Brasil & 14,3 & 393 & 3,4 & 351 & $(12,9)$ & 47,2 & 390 & $(4,8)$ & 49,5 & 407 & $(6,5)$ \\
\hline Chile & 10,5 & 432 & 1,8 & 397 & $(26,6)$ & 32,6 & 411 & $(8,2)$ & 65,6 & 447 & $(4,7)$ \\
\hline España & 20,4 & 469 & 3,8 & 490 & $(11,2)$ & 62,2 & 464 & $(3,2)$ & 34,0 & 476 & $(6,6)$ \\
\hline OECD -10 & 19,7 & 488 & 8,7 & 464 & $(5,4)$ & 54,0 & 485 & $(1,7)$ & 37,3 & 500 & $(2,9)$ \\
\hline Perú & 21,4 & 403 & 26,0 & 349 & $(7,4)$ & 60,4 & 417 & $(4,7)$ & 13,6 & 439 & $(11,4)$ \\
\hline
\end{tabular}

Fuentes: Banco Mundial, 2017; OCDE, 2017e: Tablas IV.3.1, IV.4.14, IV.4.15 y IV.4.16.

La observación de esta tabla induce a la cautela sobre los resultados financieros en PISA 2015 relacionados con la ruralidad porque:

1. La población rural de Brasil, Chile España y OCDE está infrarrepresentada en la muestra, si comparamos los datos de ruralidad de cada jurisdicción que ofrece el Banco Mundial con los de PISA 2015. Sólo se aproximan los datos de ambas fuentes en Perú.

2. El error estándar para las medias de población rural es muy elevado en varias jurisdicciones, se destacan el de Chile con un E.E. de 27, seguido de Brasil con 13 y España con 11.

3. Exceptuando España, se aprecia en estas jurisdicciones que los rurales obtienen peor puntuación financiera, y al aumentar el tamaño de población mejora el resultado. En España, el mejor resultado es rural, seguido por ciudad, y el peor resultado se da en la zona intermedia.

4. En el mismo sentido, la media rural siempre es inferior a la media estatal, exceptuando España.

\section{Discusión de resultados}

El poco tiempo transcurrido desde la publicación de los informes PISA dificulta que podamos contrastar nuestros hallazgos con los de otros investigadores. Un ejemplo es el artículo más reciente sobre PISA en América Latina y rural (Castro, Giménez y Pérez, 2017) que hemos localizado, que se centra en PISA 2012 y no aporta datos sobre rural sino opiniones. Una crítica a PISA es la falta de relación en las explicaciones con otras evaluaciones externas. En el caso de Latinoamérica se pueden contrastar datos con el SERCE y TERCE.

En el Segundo Estudio Regional Comparativo y Explicativo (SERCE) realizado en la región en 2006 para alumnos de $3 .^{\circ}$ y $6 .^{\circ}$ grados en matemáticas y lenguas, y ciencias sólo en $6 .{ }^{\circ}$, se constata la misma tendencia entre las escuelas rurales, urbanas públicas y privadas, 
pero al descontar el efecto del NSEC esas diferencias se reducen y en algunos países las rurales superan a las urbanas. Además se recalca que el índice socioeconómico es el factor que más actúa sobre los resultados de las pruebas (Treviño, 2010, pp. 89-90).

Treviño (2010, p. 128) nos indica que en América Latina y el Caribe el 40\% de las escuelas evaluadas en el SERCE se ubican en zona rural, muchas son escuelas multigrado (un docente enseña a alumnos de varios grados simultáneamente) y otras no ofrecen la educación primaria completa. En secundaria también puede existir multigrado, como las Telesecundarias de México. Cabría analizar el impacto específico rural en las competencias evaluadas y compararlo con PISA.

La Revista Iberoamericana sobre Calidad, Eficacia y Cambio en Educación - REICEpublicó en octubre de 2016 un monográfico de 182 páginas sobre el Tercer Estudio Regional Comparativo y Explicativo (TERCE) de América Latina, el cual contiene 31 referencias a rural que evidencian la importancia de lo rural en esta región, aunque no hay ningún artículo específico al respecto y casi todas ellas se concentran en dos artículos.

Los principales hallazgos de LLECE-OREALC/UNESCO (2016) son que en 20 años la región ha mejorado en educación, pero no tanto en reducción de la pobreza, persiste la inequidad y las altas tasas de población rural dificultan la expansión de la educación de calidad puesto que estas escuelas atienden a población más vulnerable, y al descontar el efecto del NSEC las diferencias entre privado, urbano y rural se reducen y tienden a desaparecer, incluso en algunos casos las rurales públicas superan a las urbanas y privadas (LLECE-OREALC/UNESCO, 2016, p. 28), confirmando los datos de SERCE y PISA. No obstante, algunas opiniones que constan en el artículo impiden la posibilidad de educación rural de calidad si no se considera que es posible sin copiar el modelo urbano.

Por su parte, en el estudio de las encuestas sobre profesorado que realiza Weinstein (2016) la ruralidad se manifiesta continuamente, y se ofrece una visión más positiva de lo rural que de lo urbano en cuanto a clima escolar: buenas relaciones entre profesores, mejor atención del alumnado, menor agresividad del alumnado y más orientación al trabajo escolar. El alumnado opina que en la rural se valoran más las actitudes de los maestros y también ocurre que los más desfavorecidos socioeconómicamente valoran más a sus profesores. A su vez, el profesorado rural interactúa más con su alumnado, lo conoce mejor y le hace participar en las clases (Weinstein, 2016, pp. 105-106), pero también presenta observaciones negativas sobre rural: el profesorado asiste menos que en la urbana y privada y sus expectativas sobre el futuro académico de sus alumnos van en el mismo orden.

Cabe resaltar que las conclusiones de TERCE 2013 para primaria "predicen” las de PISA 2015 en secundaria. Se sugiere profundizar en el TERCE consultando su web o el volumen de Pizarro (2015) 


\section{Conclusiones y propuestas}

América Latina es diversa y heterogénea, como lo son las ruralidades, y es difícil considerar los distintos factores de contexto para formular conclusiones ponderadas y justas. El factor socioeconómico tiene un papel importante en los resultados de PISA y generalmente los rurales también tienen menor índice socioeconómico NSEC que en la OCDE. En América Latina es más fuerte esta diferencia, lo que pone en evidencia una mayor segregación social y escolar.

PISA considera el factor rural en distintas publicaciones desde la primera ronda de 2000 , pero a nuestro juicio no se aborda con suficiente profundidad y en algunos informes casi ni se cita, invisibilizando la escuela rural, cuando PISA podría emplearse para evidenciar las diferencias y actuar para conseguir una educación más equitativa. Parece que se responde a la pérdida de peso de la población rural respecto del total, cuando en realidad hay muchas zonas donde la ruralidad sigue aumentando su población y debe ser atendida.

En PISA 2012 las escuelas rurales obtienen peores resultados que las urbanas públicas y éstas van a la zaga de las privadas. Pero cuando se controla el NSEC las diferencias se reducen y en algunos casos incluso se revierten (Portugal). En los países de ingresos medios ocurre lo mismo y las brechas educativas urbano-rural son patentes, por lo que parece necesario profundizar en su estudio.

El Volumen I de PISA 2015 sobre equidad y calidad incomprensiblemente no ofrece datos sobre rural, y los hemos extraído de Pisadataexplorer. Los datos de países de América Latina sobre resultados rurales indican mejoras importantes y reducción de la brecha urbano-rural en ciencias entre 2006 y 2015, que todavía existe, y en algunos países es muy superior a la media de la OCDE. Ejemplos de mejora son Chile, Brasil, México y Colombia. En la OCDE, España y Portugal las brechas son menores, pero existen, y en el caso de Portugal aumentan, por lo que no habría que tomarlo como modelo de mejora de lo rural. Estos datos de secundaria confirman los datos obtenidos en primaria en las pruebas SERCE 2006 y TERCE 2013 en América Latina.

Parece que PISA toma muestras de población rural menores de las esperadas por la cantidad de población rural estimada y muchas veces ubica en centros medios (en poblaciones de 3.000 a 15.000 habitantes) alumnado concentrado de poblaciones rurales, que no computan como tales. A esto hay que añadir las bajas tasas de finalización de secundaria 15-17 años, por lo que sus datos están sesgados al centrarse en población escolarizada. Todo ello hace pensar que las competencias "reales" en zonas rurales son inferiores a las indicadas. Además, no hemos profundizado en brechas digitales, de infraestructuras escolares y de condiciones de los hogares, generalmente inferiores en zona rural y que inciden en el NSEC y en los logros académicos. 
El volumen II de PISA 2015 sobre enseñanza de las ciencias toma muestras que infrarrepresentan las zonas rurales. Pese a ello se aprecian en los datos algunas ventajas de la rural en la enseñanza de las ciencias, como puede ser el mayor conocimiento del alumnado por parte del profesor, el considerar sus conocimientos o interactuar más con ellos. Estos aspectos positivos casi aparecen ocultos en el informe.

El volumen III de PISA 2015 sobre el bienestar del alumnado, a partir de los cuestionarios de contexto, alumnado y profesorado, aporta datos sobre acoso escolar más importantes en zonas rurales, en contra de la opinión generalizada entre los docentes y documentada en investigaciones sobre un mejor clima escolar. Cabría analizar en profundidad este hecho para saber si tiene efecto el factor territorio y existe un rechazo urbano-rural, similar al que puede producirse entre nacionales e inmigrantes. También se evidencia una mayor segregación en América Latina y unas expectativas de alcanzar grados universitarios de los estudiantes rurales inferiores al resto.

El volumen IV de PISA 2015 trata la competencia financiera en quince países, de los cuales excluye cinco por no superar el $5 \%$ de muestra rural. A nuestro juicio no es un estudio representativo, pero lo más grave es que casi oculta que los rurales de Estados Unidos y España superan ampliamente las medias en competencia financiera que en los otros ámbitos.

Parece que la OCDE en PISA 2015 no tiene interés por evidenciar las diferencias de equidad urbano-rural, puesto que siendo su brecha más fuerte que la de género apenas la analiza. Pero más grave todavía es que cuando los rurales obtienen mejores "resultados" este dato no aparezca en el texto y los investigadores tengan que recurrir a las tablas para descubrirlo. Pese a ello hemos encontrado el folleto Trends Shaping Education Spotlight 9. Country Roads: Education and Rural Life (CERI, 2017) y el blog de Marc Fuster (OCDE) que tratan la ruralidad en la OCDE, ajenos a una visión negativa de la escuela rural, donde plantean pros y contras con ponderación y formulan propuestas.

No parece que el Grupo Iberoamericano de PISA se haya reactivado desde 2009, puesto que ya no hemos encontrado publicaciones al respecto. Urge que se rearme para estudiar las múltiples fuentes de datos desde Latinoamérica, con implicación de investigadores españoles y portugueses, dando un enfoque rural a su trabajo, ya que la población rural sigue creciendo y podemos aprender unos de otros. Al mismo tiempo se debería aprovechar el amplio y profundo conocimiento desarrollado por investigadores latinoamericanos sobre educación rural (Abós, Bustos, Boix, Domingo, Vázquez, Feu, Champollion, Fauget, Alpe, Collot, Juárez, Vargas, Santos, Vera, etc.) y calidad o evaluación educativa (Román, Mizala, Cervini, Cueto, Bachkov, Treviño, Murillo, Jornet, Lizasoain) de los muchos que hay y escriben en nuestras lenguas.

Otros investigadores pueden tomar este campo como propio, porque todas las aportaciones pueden contribuir a mejorar la educación rural. La bibliografía 
adjunta puede servir para iniciar su camino y especialmente aprovechar los buenos compendios referidos (Rivas, Pizarro, Treviño, CERI, European Comission, Bugdinaté et al., Loocked et al., Unesco, Sánchez y Coto) así como sus bases de datos (OECD, PISA, LLECE, SITEAL, UNESCO, CIMA, BID).

Pese a las distintas críticas que se han vertido sobre PISA, su metodología, los errores muestrales o de pruebas de competencias, sus análisis y su instrumentalización política, es indudable que el esfuerzo para los países es grande, pero los datos que aporta pueden ayudar a mejorar, sobre todo si cada país o región intentan contextualizarlos y aprovecharlos desde sus circunstancias concretas y en relación con su región, aprovechando otras fuentes (SERCE, TERCE, Niños del Milenio, SABER, SIMCE).

Es necesario potenciar redes rurales (de escuelas, de investigadores, mixtas, con administraciones) y vincularlas a proyectos gubernamentales o de otras instituciones internacionales o fundaciones. Un ejemplo puede ser la Red Iberoamericana de Educación en Territorios Rurales - RIBETER-, la Educación para la Población Rural que se ha plasmado en el Centro Internacional de Investigación y Capacitación para la Educación Rural (INRULED: International Research and Training Centre for Rural Education) ubicado en Beijing (China), con 67 investigaciones en curso, o la implicación de los maestros rurales como investigadores (Mandujano, 2009).

\section{Referencias}

Abós Olivares, P. (2014), El modelo de escuela rural multigrado ¿es un modelo del que podamos aprender? ¿Es transferible a otro tipo de escuela? Innovación Educativa, 24, 99-118. Recuperado de: http://www.usc.es/revistas/index.php/ie/ article/view/1946/2224

Ares Abalde, M. (2014). School size policies: A literature review. OECD Education Working Papers, No. 106. Paris: OECD Publishing. Recuperado de: http:// dx.doi.org/10.1787/5jxt472ddkjl-en

Banco Mundial (2017a). Porcentaje de población rural en el mundo, 1960-2016. Recuperado de: https://datos.bancomundial.org/indicador/SP.RUR.TOTL. ZS?end $=2016 \&$ start $=1960 \&$ view $=$ chart

Banco Mundial (2017b). Población rural en el mundo, economías y países. 19602016. Recuperado de: https://datos.bancomundial.org/indicador/SP.RUR. TOTL? end $=2016 \&$ start $=1960 \&$ view $=$ chart

BID (2015). Números para el Desarrollo: portal de datos abiertos del BID Banco Interamericano de Desarrollo http://data.iadb.org

Blanco, R. (2006). La equidad y la inclusión social: uno de los desafíos de la educación y la escuela hoy. REICE-Revista Electrónica Iberoamericana sobre Calidad, Eficacia y Cambio en Educación, 4(3), 1-15.

Budginaitė, I., Siarova, H., Sternadel, D., Mackonytė, G. and Spurga, S. (2016). Policies and practices for more equality and inclusion in and through education: Evidence and policy guidance from European research projects 
funded under FP6 and FP7. NESET II report. Luxembourg: Publications Office of the European Union. Doi: 10.2766/300891

Bustos Jiménez, A. (2011). Investigación y escuela rural ¿irreconciliables? Profesorado. Revista de Currículum y Formación de Profesorado, 15(2), 155170.

Bustos Jiménez, A. (2014). La didáctica multigrado y las aulas rurales. Perspectivas y datos para su análisis. Innovación Educativa, 24, 119-131. Recuperado de: http:/www.usc.es/revistas/index.php/ie/article/view/1994/2272

Castro Aristizábal, G., Giménez, G., Pérez Ximénez-de-Embún, D. (2017, abriljunio). Desigualdades educativas en América Latina, PISA 2012: causas de las diferencias en desempeño escolar entre los colegios públicos y privados. Revista de Educación, 376, 33-61. DOI: 10.4438/1988-592X-RE-2017-376-343

CERI (2017). Trends Shaping Education Spotlight 9. Country Roads: Education and Rural Life. Centre for Educational Research and Innovation CERI/OCDE. 12 p. Recuperado de: http://www.oecd.org/edu/ceri/spotlight9-CountryRoads. pdf

CIMA (2017). Centro de Información para la Mejora de los Aprendizajes. Banco Interamericano de Desarrollo. Recuperado de: http://www.iadb.org/es/basesde-datos/cima/inicio,20590.html?

Contreras Salinas, S. (2010). Aproximación al acontecer educativo en contextos rurales. Revista Digital eRural. Educación, cultura y desarrollo rural, 13-14. Recuperado de: http://www.revistaerural.cl

Domingo, L., Boix, R. y Champollion, P. (2012). Estado de la cuestión del Proyecto de Investigación Educativa "La eficacia y calidad en la adquisición de competencias caracterizan a la escuela rural: ¿es un modelo transferible a otra tipología de escuela?”. Educaçao: Santa Maria. Recuperado de: http:// cascavel.ufsm.br/revistas/ojs-2.2.2/index.php/reveducacao/article/view/4132 [Consultado el 4 de febrero de 2015]

EACEA(2010).Pruebas nacionales de evaluación delalumnadoen Europa:objetivos, organización y utilización de los resultados. Madrid: Agencia Ejecutiva en el Ámbito Educativo, Audiovisual y Cultural. EACEA/P9 EURYDICE. Comisión Europea - Ministerio de Educación. Recuperado de: http://eacea.ec.europa.eu/ education/eurydice/documents/thematic_reports/109ES.pdf

European Comission (2016). PISA 2015. EU Performance and initial conclusions regarding education policies in Europe. Directorate-General for Education and Culture. European Comission. Recuperado de https://ec.europa.eu/education/ sites/education/files/pisa-2015-eu-policy-note_en.pdf

Freire, P. (1982). Pedagogía del oprimido. México: Siglo XXI.

Fuster, Marc (2017). Caminos rurales: educación y vida rural. OCDE/Education today. Recuperado de: http://oecdeducationtoday.blogspot.com.es/2017/04/ country-roads-education-and-rural-life.html

GIP (2009). Iberoamérica en PISA 2006. Informe regional. México: Grupo Iberoamericano de PISA. OCDE / Santillana. México.

INRULED (2017). International Research and Training Centre for Rural Education. Recuperado de: http://www.inruled.org/en/ 
Itzcovich, G. (2010). Contextos rurales. Continuidades y rupturas en el acceso a la educación. Cuaderno 05. SITEAL-OEI, IIPE-UNESCO. Oficina Regional Buenos Aires. Recuperado de: http://www.siteal.iipe.unesco.org/cuadernos/254/ educacion-en-contextos-rurales

Itzcovich, G. (2012). Configuraciones espaciales de escenarios urbanos y rurales. Desafíos pendientes en los procesos de inclusión educativa. Cuaderno 12. SITEAL-OEI, IIPE-UNESCO. Oficina Regional Buenos Aires. Recuperado de: http://www.siteal.iipe.unesco.org/cuadernos/338/configuraciones-espacialesde-escenarios-urbanos-y-rurales

Jornet Melià, J. M. (2016). Análisis metodológico del Proyecto PISA como evaluación internacional. RELIEVE, 22(1), 1-25. Recuperado de: http://dx.doi. org/10.7203/relieve22.1.8293

Juárez Bolaños, D. y Rodríguez Solera, C.R. (2016). Factores que afectan a la equidad educativa en escuelas rurales de México. Pensamiento Educativo. Revista de Investigación Educacional Latinoamericana, 53(2), 1-15. Recuperado de: http://pensamientoeducativo.uc.cl/files/journals/2/articles/797/public/7973021-1-PB.pdf

Kit, I., Scasso, M., España, S. y Morduchowicz, A. (2012). Completar la escuela. Un derecho para crecer, un deber para compartir. Resumen ejecutivo. Balboa, Panamá: UNESCO-UNICEF/Oficina Regional para América Latina y El Caribe. Balboa. Panamá. Recuperado de: http://unesdoc.unesco.org/ images/0021/002176/217669s.pdf

LLECE (2014). Primera entrega de resultados. Tercer Estudio Regional Comparativo y Explicativo. Comparación de resultados del segundo y tercer estudio regional comparativo y explicativo SERCE Y TERCE 2006-2013. Laboratorio Latinoamericano de Evaluación de la Calidad de la Educación / UNESCO-OREALC. Santiago de Chile.

LLECE-OREALC/UNESCO (2016). Informe de Resultados del Tercer Estudio Regional Comparativo y Explicativo (TERCE). REICE. Revista Iberoamericana sobre Calidad, Eficacia y Cambio en Educación, 14(4), 93-111.

Lockheed, M., Prokic-Bruer, T. \& Shadrova, A. (2015). The Experience of Middle-Income Countries Participating in PISA 2000-2015. Washington: The World Bank; Paris: D.C./OECD Publishing. Recuperado de: http://dx.doi. org/10.1787/9789264246195-en

Mandujano Bustamante, F. (2009, enero). Cómo la escuela rural puede propiciar la investigación educacional pertinente. Revista Digital eRural, Educación, cultura y desarrollo rural, :(11-12). Recuperado de: http://www.revistaerural.cl/ ojs/index.php/RER/article/view/31/

Martínez-Rizo, Felipe (2016). Impacto de las pruebas en gran escala en contextos de débil tradición técnica: Experiencia de México y el Grupo Iberoamericano de PISA. RELIEVE, 22(1), 1-12. Recuperado de: http://dx.doi.org/10.7203/ relieve.22.1.8244

Murillo Torrecilla, F. Javier (Coord.) (2016, octubre). Monográfico: La educación en América Latina y el Caribe. Aportes del TERCE y sus reanálisis. REICE. Revista Iberoamericana sobre Calidad, Eficacia y Cambio en Educación, 14(4). 
doi: 10.15366/reice2016.14.4 https://revistas.uam.es/index.php/reice/issue/ download/624/325

OECD (2000). Measuring Student Knowledge and Skills: The PISA 2000 Assessment of Reading, Mathematical and Scientific Literacy. Paris: OECD Publishing. Recuperado de: http://dx.doi.org/10.1787/9789264181564-en

OECD (2001). Knowledge and Skills for Life: First Results from PISA 2000. Paris: OECD Publishing. Recuperado de: http://dx.doi.org/10.1787/9789264195905-en OECD (2002a). PISA 2000 Technical Report. Paris: OECD Publishing. Recuperado de: https://www.oecd.org/pisa/data/33688233.pdf

OECD (2002b). Sample Tasks from the PISA 2000 Assessment: Reading, Mathematical and Scientific Literacy Paris: OECD Publishing. Recuperado de: http://dx.doi.org/10.1787/9789264194274-en

OECD (2002c). Programme for International Student Assessment (PISA): Manual for the PISA 2000 Database. Paris: OECD Publishing. Recuperado de: http:// dx.doi.org/10.1787/9789264176201-en

OECD/UIS (2003). Literacy Skills for the World of Tomorrow: Further Results from PISA 2000. Paris: Unesco Institute for Statistics UIS, OECD Publishing. Recuperado de: http://dx.doi.org/10.1787/9789264102873-en

OECD (2004). Learning for Tomorrow's World: First Results from PISA 2003. Paris: OECD Publishing. Recuperado de: http://dx.doi.org/10.1787/9789264006416-en OECD (2005a). School Factors Related to Quality and Equity: Results from PISA 2000. Paris: OECD Publishing. Recuperado de: http://dx.doi. org/10.1787/9789264008199-en

OECD (2005b). PISA 2003 Data Analysis Manual: SPSS. Paris: OECD Publishing. Recuperado de: http://dx.doi.org/10.1787/9789264010666-en

OECD (2006). Messages from PISA 2000. Paris: OECD Publishing. Recuperado de: http://dx.doi.org/10.1787/9789264018761-en

OECD (2007). PISA 2006: Science Competencies for Tomorrow's World. Volume 1: Analysis. Paris: OECD Publishing. Recuperado de: http://dx.doi. org/10.1787/9789264040014-en

OECD (2008a). PISA 2006: Volume 2: Data. Paris: OECD Publishing. Recuperado de: http://dx.doi.org/10.1787/9789264040151-en

OECD (2008b). PISA 2006. Volume 2: Table 5.21b: Effects of significant school factors and demographic and socio-economic factors on student performance in science, by country. Recuperado de: http://dx.doi.org/10.1787/142127877152

OECD (2010). PISA 2009 Results: Overcoming Social Background: Equity in Learning Opportunities and Outcomes (Volume II). Paris: OECD Publishing. Recuperado de: http://dx.doi.org/10.1787/9789264091504-en

OECD (2011). PISA 2009 Results: (Volume II), Table II.2.6. Reading performance and socio-economic background, by school location. Recuperado de: http:// dx.doi.org/10.1787/888932381418

OECD (2013a). PISA 2012 Results: Excellence Through Equity: Giving Every Student the Chance to Succeed (Volume II). Paris: OECD Publishing. Recuperado de: http://dx.doi.org/10.1787/9789264201132-en 
OECD (2013b). Tabla II.3.3a. Relación entre desempeño en matemáticas y localización de la escuela. En PISA 2012 Results: Excellence through Equity (Volume II). Paris: OECD Publishing. Recuperado de: http://dx.doi. org/10.1787/9789264201132-table88-en

OECD (2013c). Tabla II.3.3b. Cambio entre 2003 y 2012 en el desempeño en matemáticas y localización de la escuela. En PISA 2012 Results: Excellence through Equity (Volume II). Paris: OECD Publishing. Recuperado de: http:// dx.doi.org/10.1787/9789264201132-table89-en

OECD (2014). PISA 2012 Results: What Students Know and Can Do (Volume I, Revised edition, February 2014): Student Performance in Mathematics, Reading and Science. Paris: OECD Publishing. Recuperado de: http://dx.doi. org/10.1787/9789264208780-en

OECD (2016a). PISA 2015 Results (Volume I): Excellence and Equity in Education. Paris: OECD Publishing. Recuperado de: http://dx.doi. org/10.1787/9789264266490-en

OECD (2016b). PISA 2015 Results (Volume II): Policies and Practices for Successful Schools. Paris: OECD Publishing. Recuperado de: http://dx.doi. org/10.1787/9789264267510-en

OECD (2016c). Table B1.2. Results (tables): How schools and school systems shape students' performance in and dispositions towards science. In PISA 2015 Results (Volume II), Paris: OECD Publishing. Recuperado de: http://dx.doi. org/10.1787/9789264267510-table103-en

OECD (2017a). PISA 2015 Results (Volume III): Students' Well-Being. Paris: OECD Publishing. Recuperado de: http://dx.doi.org/10.1787/9789264273856-en

OECD (2017b). PISA 2015 Results (Volume IV): Students' Financial Literacy. Paris: Éditions OCDE. Recuperado de: http://dx.doi.org/10.1787/9789264270282-en

OCDE/CEPAL (2011). Perspectivas Económicas de América Latina 2012: Transformación del Estado para el Desarrollo. Paris: OECD Publishing. Recuperado de: http://dx.doi.org/10.1787/leo-2012-es

Pizarro, Atilio et al. (2015). Tercer Estudio Regional Comparativo y Explicativo TERCE. Informe de resultados. Cuadernillo 3. Factores asociados. Santiago de Chile: LLECE / UNESCO-OREALC. Santiago de Chile.

Quílez Serrano, M. y Vázquez Recio, R. (2012). Aulas multigrado o el mito de la mala calidad de enseñanza en la escuela rural. Revista Iberoamericana de Educación / Revista Ibero-americana de Educação, 59/2, 1-12. Recuperado de: http://www.rieoei.org/rie_contenedor.php?numero=5353\&titulo=Aulas $\% 20$ multigrado\%200\%20el\%20mito\%20de\%

Rivas, A. (2015). América Latina después de PISA: Lecciones aprendidas de la educación en siete países (2000-2015). Buenos Aires: CIPPEC-Instituto Natura. Recuperado de: http://mapeal.cippec.org/wp-content/uploads/2015/05/ Rivas_A_2015_America_Latina_despues_de_PISA.pdf

Sánchez, B. y Coto, P. (2016). Inspiraciones alcanzables: 15 políticas educativas destacadas en América Latina. Buenos Aires: CIPPEC-Instituto Natura. Recuperado de: htps://www.cippec.org/publicacion/inspiraciones-alcanzables15-politicas-educativas-destacadas-en-america-latina/ 
Santamaría Luna, Rogeli (1996). La escuela rural entre 1970 y 1990. Zona del río Villahermosa (Tesis doctoral). Universitat Jaume I. Castelló, Recuperado de: http://hdl.handle.net/10803/84066

Santamaría Luna, R. (2012, noviembre). Inspección de Educación y Escuela Rural. Contra el mito del bajo rendimiento de la escuela rural. Visión histórica 1972-2012. Avances en Supervisión Educativa. Revista de la Asociación de Inspectores de Educación de España, 17, 1-29. Recuperado de: http://www. adide.org/revista/images/stories/revista17/ase17_monoo4.pdf

Santamaría Luna, R. (2015a). La educación personalizada en la escuela rural. Encuentro de Educación Personalizada en la Era Digital EPEDIG (pp. 74-92). Universidad Internacional de La Rioja, Logroño, 24-26 de junio de 2014. pp. 74-92. Recuperado de: http://personalizada.jimdo.com/app/download/10444188399/ Libro_actas_primer_encuentro_EPEDIG.pdf

Santamaría Luna, R. (2015b, noviembre). Escuela rural y evaluaciones externas. Forum Aragón. Revista digital del Fórum Europeo de Administradores de la Educación de Aragón sobre organización y gestión educativa, V(16), 49-57. Recuperado de: http://feae.eu/wp-content/uploads/2015/11/Revista_Digital_ Forum_Aragon16.pdf

Santamaría Luna, R. (2015c, diciembre). El abandono escolar prematuro en zonas rurales de España y de Europa. Avances en supervisión educativa, 24, 1-44 Recuperado de: http://www.adide.org/revista/images/stories/revista24/ ase_24_17_santamaria.pdf

SITEAL (2017). Sistema de Información de Tendencias Educativas en América Latina. Recuperado de: http://www.siteal.iipe.unesco.org/

TERCE: Tercer Estudio Regional Comparativo y Explicativo. OREALC-UNESCO, Santiago http://www.unesco.org/new/es/santiago/terce/

Treviño, E. et al. (2010). SERCE. Factores asociados al logro cognitivo de los estudiantes en América Latina y el Caribe. Santiago de Chile: LLECE / UNESCO-OREALC.

Unesco (2015). La Educación para Todos, 2000-2015: logros y desafíos. París: Ediciones Unesco. París. Recuperado de: http://unesdoc.unesco.org/ images/0023/002324/232435s.pdf

Unesco (2017). Educación. Temas. Poblaciones rurales. Recuperado de: http:// www.unesco.org/new/es/education/themes/strengthening-education-systems/ inclusive-education/rural-people/

UIS (2016). Making Education Count for Development: Data Collection and Availability in Six PISA for Development Countries. Paris: Unesco Institute for Statistics UIS / OECD Publishing. Recuperado de: http://dx.doi. org/10.1787/9789264255449-en

Weinstein, José (2016). ¿Cómo vivencian los docentes latinoamericanos su trabajo y su escuela? Nuevos antecedentes a partir del estudio TERCE. REICE. Revista Iberoamericana sobre Calidad, Eficacia y Cambio en Educación, 14(4), 93-111. 